Linköping Studies in Science and Technology

Dissertation No. 1626

\title{
On Thermomechanical Fatigue of Single-Crystal Superalloys
}

\section{Mikael Segersäll}

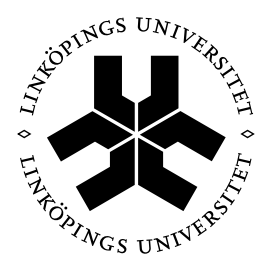

\section{Linköping University INSTITUTE OF TECHNOLOGY}

\author{
Division of Engineering Materials \\ Department of Management and Engineering \\ Linköping University, SE-58183, Linköping, Sweden \\ www.liu.se
}

Linköping, November 2014 
Opponent: Ass. Prof. Jonathan Cormier, ISAE-ENSMA, Institut Pprime, France Defend date: November 28, 2014

Room: ACAS, Linköping University

Thesis cover: Design by Maria J. Segersäll

Printed by:

LiU-Tryck, Linköping, Sweden, 2014

ISBN 978-91-7519-211-6

ISSN 0345-7524

Distributed by:

Division of Engineering Materials, Department of Management and Engineering Linköping University

SE-58183, Linköping, Sweden

두 2014 Mikael Segersäll

This document was prepared with $\mathrm{H}_{\mathrm{E}} \mathrm{T} \mathrm{X}$, October 17, 2014 


\section{Abstract}

Thanks to their excellent mechanical and chemical properties at temperatures up to $1000{ }^{\circ} \mathrm{C}$, nickel-based superalloys are used in critical components in high-temperature applications such as gas turbines and aero engines. One of the most critical components in a gas turbine is the turbine blade, and to improve the creep and fatigue properties of this component, it is sometimes cast in single-crystal form rather than in the more conventional polycrystalline form. Gas turbines are most commonly used for power generation and the turbine efficiency is highly dependent on the performance of the superalloys.

Today, many gas turbines are used as a complement for renewable energy sources, for example when the wind is not blowing or when the sun is not shining, which means that the turbine runs differently compared to earlier, when it ran for longer time periods with a lower number of start-ups and shutdowns. This new way of running the turbine, with an increased number of start-ups and shut-downs, results in new conditions for critical components, and one way to simulate these conditions is to perform thermomechanical fatigue (TMF) testing in the laboratory. During TMF, both mechanical strain and temperature are cycled at the same time, and one fatigue cycle corresponds to the conditions experienced by the turbine blade during one start-up and shut-down of the turbine engine.

In the work leading to this $\mathrm{PhD}$ thesis, TMF testing of single-crystal superalloys was first performed in the laboratory and this was then followed microstructure investigations to study the occurring deformation and damage mechanisms. Specimens with different crystallographic directions have been tested in order to investigate the anisotropic behaviour shown by these materials. Results show a significant orientation dependence during TMF in which specimens with a low elastic stiffness perform better. However, it is also shown that specimens with a higher number of active slip systems perform better during TMF compared to specimens with less active slip sys- 
tems. This is because a higher number of active slip systems results in a more widespread deformation and seems to be beneficial for the TMF life. Further, microscopy shows that the deformation during TMF is localised to several deformation bands and that different deformation and damage mechanisms prevail according to in which crystal orientation the material is loaded. Deformation twinning is shown to be a major deformation mechanism during TMF and the interception of twins seems to trigger recrystallization. This is certainly negative for the mechanical properties of single-crystal superalloys since no grain boundary strengthening elements are added to these materials, and therefore grain boundaries can be considered as weak points at which crack initiation and propagation may occur.

The effect of long dwell-times during TMF has also been studied in this work. Both a significant tension/compression asymmetry and an anisotropic behaviour, is shown to be prevalent during creep relaxation at high temperatures. It is also shown that similar creep rates can be obtained from the more time-efficient TMF creep relaxation tests as from the more time-consuming constant load creep tests. Creep rates are, for example, needed when performing material modelling and if these can be obtained more quickly, it can be of great importance for gas turbine industry. This work also studies the effects of alloying a single-crystal superalloy with $\mathrm{Si}$ or Re, and results show a significant Si-effect where the TMF life increases by a factor of 2 when $\mathrm{Si}$ is added to the alloy.

Finally, this research results in an increased knowledge of the mechanical response as well as a deeper understanding of the deformation and damage mechanisms that occur in single-crystal superalloys during TMF. It is believed that in the long-term, this can contribute to a more efficient and reliable power generation by gas turbines.

Keywords: thermomechanical fatigue, deformation mechanism, twin, anisotropy, tension/compression asymmetry. 


\section{Populärvetenskaplig sammanfattning på svenska}

\section{Kan ett material bli utmattat?}

Absolut! När ett material belastas första gången bildas ofta små sprickor inuti materialet som inte syns med blotta ögat och man kan därmed tro att materialet är helt opåverkat. Men, om materialet blir utsatt för upprepade belastningar kommer dessa små sprickor att växa och till slut leda till att materialet havererar. Då ett material utsätts för upprepade belastningar kallas det för utmattning, och detta kan i värsta fall leda till utmattningsbrott.

Att ett material havererar pågrund av utmattning behöver i vissa fall inte ha någon större betydelse, till exempel att stiftet i en blyertspenna ibland går sönder. I andra sammanhang kan däremot ett utmattningsbrott vara mer riskfyllt, till exempel, om en komponent i ett flygplan havererar när planet är i luften kan detta få katastrofala följder. Att material i kritiska komponenter blir utsatta för utmattning är inget man helt kan undvika, istället gäller det att ha tillräcklig kännedom om materialet för att på så sätt kunna förutspå haverier. Forskningen som presenteras i denna doktorsavhandling handlar om utmattning i material som används i gasturbiner, men då en flygmotor och en gasturbin är väldigt lika i sin funktion, kan resultatet från forskningen lika gärna användas från ett flygmotorperspektiv.

Gasturbiner används först och främst för att generera el, och i ett steg mot mer effektiva energikällor ställs även krav på effektivare gasturbiner. En turbins effektivitet beror till stor del av materialen som används i turbinens kritiska komponenter, till exempel en turbinskovel. Då temperaturen i en turbinskovel ibland överstiger $1000{ }^{\circ} \mathrm{C}$, samtidigt som den utsätts för extrema mekaniska laster, betyder det att material med mycket specifika egenskaper måste användas. Superlegeringar är en materialgrupp med superegenskaper vid höga temperaturer vilket gör de lämpliga för dessa applikationer. Dessa 
material är mycket komplexa och innehåller ofta fler än tio legeringsämnen och där varje ämne tillför specifika egenskaper. De består till största delen av nickel, medan andra legeringsämnen till exempel kan vara aluminium, titan, kisel och krom.

Idag används gasturbiner mer och mer som ett ett komplement till andra energikällor, till exempel när solen inte skiner eller när vinden inte blåser. Detta gör att sättet som turbinerna används på, med fler start och stopp, skiljer sig väsentligt mot tidigare där turbinen inte startades och stoppades i samma omfattning. När en turbin startas, börjar turbinskovlarna rotera och de utsätts för stora centrifugallaster samtidigt som temperaturen ökar. När turbinen sedan stängs av slutar skovlarna att rotera och temperaturen sjunker. Den ökande omfattningen av start och stopp leder till termomekanisk utmattning (både temperatur och last påverkar materialet) i turbinskovlarna, och till slut kan detta leda till haveri.

Mer specifikt handlar denna forskning om vad som händer inuti en superlegering när den utsätts för termomekanisk utmattning. I laboratoriet har provning genomförts där man försökt simulera de temperaturer och laster som en turbinskovel utsätts för i drift. Vidare har materialet senare undersökts med olika metoder för att förstå dess beteende. Resultatet från forskningen kan först och främst användas av turbintillverkare för att på ett bättre sätt kunna prediktera livslängden hos en turbinskovel, men det bidrar även till en djupare kunskap inom området som kan användas i utvecklingen av nya material. I det långa loppet kan detta leda till en mer effektiv och säkrare elproduktion. Men som sagt, då en flygmotor är väldigt lik en gasturbin i sin funktion, kan resultatet även användas i utvecklingen av nya och mer bränsleeffektiva flygmotorer.

Så än en gång, visst kan ett material bli utmattat! Men genom en ökad kunskap om materialen kan man på ett bättre sätt förutspå detta, och haverier kan därmed undvikas. 


\section{Acknowledgements}

When I am writing the final words of this thesis more than 4 years have passed since I started my $\mathrm{PhD}$ work in fall 2010. It is a strange feeling when all pieces of the puzzle finally have fallen into place. During this time a lot of things have happened, both on a professional and personal level, which all have contributed in some way to the final result; this book. Already from the beginning of my time as $\mathrm{PhD}$ student, I have combined research with undergraduate teaching, and the meetings with the students are really something that has given me a lot. As for life in general, some days have been more demanding than others. However, even when spending endless ours in front of the microscope, or when getting a number of expensive TMF tests ruined by the summer thunder, I never for one moment doubted that this was my path to go.

During the work that has led to this thesis many people have been involved for whom I would like to express my gratitude for. First and foremost I would like to thank my supervisor, Johan Moverare. Thank you for giving me this opportunity, for believing in me and for always taking your time. I am looking forward to continue our collaboration in the future.

Gratitude is also owed to the Swedish Energy Agency, Elforsk and Siemens Industrial Turbomachinery for financing this project through KME. An extra thank you goes to Siemens in Finspång for providing materials, test data and invaluable knowledge in the area of superalloys.

At Linköping University I also would like to acknowledge my co-supervisors Daniel Leidermark, Sten Johansson and Kjell Simonsson for profitable discussions during the project. A collective thank you goes to the whole Engineering Materials group for creating such great working atmosphere. Our collective trip to Beijing was amazing, and especially I would like to thank my Chinese friends Ru Peng, Kang Yuan, Zhe Chen and Wenjun Xi for making the trip to the northern capital a memory for life. Further, I would like 
to thank our administrator Ingmari Hallkvist for always being helpful. Annethe Billenius and Patrik Härnman are also acknowledged for support in the laboratory during this work.

I also would like to take the opportunity to thank all the great IEI PhD students I got to know during these years. Uni, I didn't manage to write a $\mathrm{PhD}$ thesis containing 300 pages like you did, anyhow, thank you for involving me in the IEI PhD network. And Olle, thank you for great friendship and for dragging me to the IEI gym for almost 3 years.

Finally I would like to express my deepest appreciation to my friends and family. Mum and dad, my two role models, thank you for your endless love and support. My sisters and brother, Maria, Matilda and Viktor, I cannot imagine having better people so close to me. And Maria, thank you for once again designing a beautiful cover of an academic thesis. Ingrid, you came in a hot summer day and changed my world. When I come home from work and see your smiling face, you remind me what really matters here in life. Åsa, my wife and forever best friend, thank you for your patience during the last intense work of this thesis. Our journey through life has only begun, and I am looking forward to spending the future with you. All love.

Mikael

Linköping, October 2014 


\section{List of papers}

The following papers have been included in this thesis with my own contribution to each paper stated below.

I. M. Segersäll and J. J. Moverare, "Crystallographic orientation influence on the serrated yielding behavior of a single-crystal superalloy," Materials, vol. 6, no. 2, pp. 437-444, 2013.

I performed the microstructure investigations and was the main contributor of the manuscript writing. The mechanical testing was performed by Johan J. Moverare.

II. M. Segersäll, J. J. Moverare, D. Leidermark, and K. Simonsson, "Lowcycle fatigue behaviour of a Ni-based single-crystal superalloy" $A d$ vanced Materials Research, vol. 891-892, pp. 416-421, 2014.

I performed the microstructure investigations and was the main contributor of the manuscript writing. The LCF tests were performed by Siemens Industrial Turbomachinery.

III. M. Segersäll, J. J. Moverare, D. Leidermark, and S. Johansson, "In- and out-of phase thermomechanical fatigue of a Ni-based single-crystal superalloy." in EUROSUPERALLOYS 2014 - 2 ${ }^{\text {nd }}$ European Symposium on Superalloys and Their Applications (J. Y. Guédou and J. Choné, eds.), 19003-p.1-19003-p.6, MATEC Web of Conferences, vol. 14, 2014.

I performed the TMF tests, the microstructure investigations and was the main contributor of the manuscript writing. 
IV. M. Segersäll, J. J. Moverare, K. Simonsson, and S. Johansson, "Deformation and damage mechanisms during thermomechanical fatigue of a single-crystal superalloy in the $\langle 001\rangle$ and $\langle 011\rangle$ directions," in $S u$ peralloys 2012 (E. S. Huron, R. C. Reed, M. Hardy, M. J. Mills, R. E. Montero, P. D. Portella, and J. Talesman, eds.), pp. 215-223, The Minerals, Metals and Materials Society, 2012.

I performed the microstructure investigations and was the main contributor of the manuscript writing. The TMF tests were performed by Siemens Industrial Turbomachinery

V. M. Segersäll, J. J. Moverare, D. Leidermark, and K. Simonsson, "Creep and stress relaxation anisotropy of a single-crystal superalloy." Metallurgical and Materials Transactions A, vol. 45A, pp. 2532-2544, 2014.

I performed the TMF stress relaxation tests, the microstructure investigations and was the main contributor of the manuscript writing. The long term creep tests were performed by Siemens Industrial Turbomachinery.

VI. D. Leidermark and M. Segersäll, "Modelling of thermomechanical fatigue stress relaxation in a single-crystal nickel-base superalloy." Computational Materials Science, vol. 90, pp. 61-70, 2014.

For this paper, Daniel Leidermark did the modelling part and was the main contributor of the manuscript writing. I performed the TMF stress relaxation tests and co-authored the manuscript.

VII. M. Segersäll, D. Leidermark, and J. J. Moverare "Influence of crystal orientation on the thermomechanical fatigue behaviour in a singlecrystal superalloy." Submitted.

I performed the TMF tests, the microstructure investigations and was the main contributor of the manuscript writing together with Daniel Leidermark. Daniel Leidermark performed the parts dealing with the finite element perspective. 
VIII. M. Segersäll, P. Kontis, S. Pedrazzini, P. A. J. Bagot, M. P. Moody, J. J. Moverare, and R. C. Reed, "Thermal-mechanical fatigue behaviour of a new single-crystal superalloy: Effects of $\mathrm{Si}$ and Re alloying." In manuscript.

I performed the SEM and STEM investigations, some of the TMF tests and was the main contributor of the manuscript writing. The remaining TMF tests as well as the long term creep tests were performed by Siemens Industrial Turbomachinery while the atom probe analysis was performed by Paraskevas Kontis, Stella Pedrazzini, Paul A.J. Bagot, Michael P. Moody and Roger C. Reed at the University of Oxford.

Papers not included in this thesis:

IX. D. Leidermark, J. Moverare, M. Segersäll, K. Simonsson, S. Sjöström, and S. Johansson, "Evaluation of fatigue crack initiation in a notched single-crystal superalloy component," Procedia Engineering, vol. 10, pp. 619-624, 2011.

X. J. J. Moverare, M. Segersäll, A. Sato, S. Johansson, and R. C. Reed, "Thermomechanical fatigue of single-crystal superalloys: Influence of composition and microstructure," in Superalloys 2012 (E. S. Huron, R. C. Reed, M. Hardy, M. J. Mills, R. E. Montero, P. D. Portella, and J. Talesman, eds.), pp. 369-377, The Minerals, Metals and Materials Society, 2012.

XI. M. Segersäll, J. J. Moverare, D. Leidermark, and K. Simonsson, "High temperature stress relaxation of a Ni-based single-crystal superalloy," $13^{\text {th }}$ International Conference on Fracture, Beijing, China, 2013.

XII. D. Leidermark, M. Segersäll, J. J. Moverare, and K. Simonsson, "Modelling of TMF crack initiation in smooth single-crystal superalloy specimens" Advanced Materials Research, vol. 891-892, pp. 1283-1288, 2014. 



\section{Contents}

$\begin{array}{lll}\text { Abstract } & \text { iii }\end{array}$

Populärvetenskaplig sammanfattning på svenska v

Acknowledgements vii

List of papers $\quad$ ix

Contents xiii

Abbreviations $\quad$ xvii

Part I Background \& Theory 1

1 Introduction 3

1.1 Challenges for a flexible and efficient power generation ... . 4

1.2 Background and aims of the research project . . . . . . . 4

1.3 Aims and research questions of the $\mathrm{PhD}$ work . . . . . . 5

1.4 Scope of the $\mathrm{PhD}$ thesis $\ldots \ldots \ldots \ldots$

$1.5 \mathrm{PhD}$ thesis outline $\ldots \ldots \ldots \ldots \ldots$

2 Gas turbines 9

2.1 General description . . . . . . . . . . . . . . . . . . 10

2.2 The gas turbine blade . . . . . . . . . . . . . . . . . 11

2.3 Superalloys . . . . . . . . . . . . . . . . . . . 12

2.4 The gas turbine blade in single-crystal form . . . . . . . . 13

3 Ni-based superalloys $\quad 15$

3.1 Single-crystal vs. poly-crystal superalloys . . . . . . . . . 16

3.2 Composition and phases . . . . . . . . . . . . . 16 
3.2.1 The typical $\gamma / \gamma^{\prime}$-microstructure $\ldots \ldots \ldots \ldots . \ldots 16$

3.2 .2 Other phases . . . . . . . . . . . . . . . . . . . 19

3.2 .3 Alloying elements . . . . . . . . . . . . . . . 20

3.3 Some remarkable mechanical properties . . . . . . . . . . . . 21

3.3.1 Yield strength temperature dependence . . . . . . . . . 21

3.3.2 Tension/compression asymmetry . . . . . . . . . 23

3.4 The crystal orientation influence on elastic and in-elastic properties . . . . . . . . . . . . . . . . . . 24

3.4 .1 Elasticity . . . . . . . . . . . . . . . . . . . 24

3.4.2 Yielding behaviour . . . . . . . . . . . . . . 25

4 Factors influencing the thermomechanical fatigue behaviour 27

4.1 Rafting. . . . . . . . . . . . . . . . . . . 28

4.2 Isothermal fatigue . . . . . . . . . . . . . . . 30

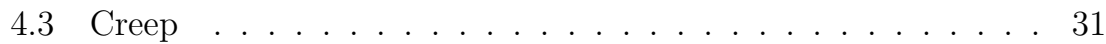

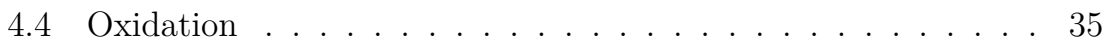

5 Thermomechanical fatigue 37

5.1 Thermomechanical fatigue: some general comments . . . . . . 38

5.2 Thermomechanical fatigue: a literature review . . . . . . . . 40

5.3 Thermomechanical fatigue from a gas turbine perspective . . . 45

6 STAL-15 - a new superalloy 49

6.1 General information . . . . . . . . . . . . . . . . 50

6.2 Properties ........................... 51

7 Experimental work $\quad 53$

7.1 Material . . . . . . . . . . . . . . . . . 54

7.2 Thermomechanical fatigue testing . . . . . . . . . . 54

7.3 Stereomicroscopy . . . . . . . . . . . . . . . . 55

7.4 Scanning electron microscopy . . . . . . . . . . . . 55

7.5 Scanning transmission electron microscopy . . . . . . . . 56

8 Review and discussion of papers included $\quad 57$

9 Conclusions and contribution $\quad 65$

9.1 Conclusions . . . . . . . . . . . . . . . . . 66

9.2 Contribution . . . . . . . . . . . . . . . . 67

10 Suggestions for further research $\quad 69$

$\begin{array}{ll}\text { Bibliography } & 71\end{array}$

xiv 
Paper I: Crystallographic orientation influence on the serrated yielding behavior of a single-crystal superalloy

Paper II: Low-cycle fatigue behaviour of a Ni-based single-crystal superalloy

Paper III: In- and out-of-phase thermomechanical fatigue of a Ni-based single-crystal superalloy

Paper IV: Deformation and damage mechanisms during thermomechanical fatigue of a single-crystal superalloy in the $\langle 001\rangle$ and $\langle 011\rangle$ directions

Paper V: Creep and stress relaxation anisotropy of a singlecrystal superalloy

Paper VI: Modelling of thermomechanical fatigue stress relaxation in a single-crystal nickel-base superalloy

Paper VII: Influence of crystal orientation on the thermomechanical fatigue behaviour in a single-crystal superalloy

Paper VIII: Thermal-mechanical fatigue behaviour of a new single-crystal superalloy: Effects of Si and Re alloying 



\section{Abbreviations}

$\begin{array}{ll}\text { APB } & \text { Anti-Phase Boundary } \\ \text { BCC } & \text { Body Centered Cubic } \\ \text { BCT } & \text { Body Centered Tetragonal } \\ \text { CCD TMF } & \text { Counter Clockwise Diamond ThermoMechanical Fatigue } \\ \text { CD TMF } & \text { Clockwise Diamond ThermoMechanical Fatigue } \\ \text { CRSS } & \text { Critical Resolved Shear Stress } \\ \text { DS } & \text { Directionally Solidified } \\ \text { DSA } & \text { Dynamic Strain Ageing } \\ \text { EBSD } & \text { Electron BackScattering Diffraction } \\ \text { ECCI } & \text { Electron Channeling Contrast Imaging } \\ \text { FCC } & \text { Face Centered Cubic } \\ \text { FE } & \text { Finite Element } \\ \text { IP TMF } & \text { In-Phase ThermoMechanical Fatigue } \\ \text { LCF } & \text { Low Cycle Fatigue } \\ \text { OIM } & \text { Orientation Imaging Microscopy } \\ \text { OP TMF } & \text { Out-of-Phase ThermoMechanical Fatigue } \\ \text { RT } & \text { Room Temperature } \\ \text { SEM } & \text { Scanning Electron Microscopy } \\ \text { SESF } & \text { Super Extrinsic Stacking Fault } \\ \text { STEM } & \text { Scanning Transmission Electron Microscopy } \\ \text { TBC } & \text { Thermal Barrier Coating } \\ \text { TCP } & \text { Topologically Close Packed } \\ \text { TEM } & \text { Transmission Electron Microscopy } \\ \text { TMF } & \text { ThermoMechanical Fatigue }\end{array}$





\section{Part I}

Background \& Theory 



\section{1 \\ Introduction}

This first chapter introduces the motivation behind the research that has led to this PhD thesis, and briefly discusses some of the challenges for future power generation. This chapter also addresses the background and aims of the research project generally, as well the background and aims of the PhD work specifically. Research questions are stated and a short description of the scope of the thesis is presented and outlined. 


\subsection{Challenges for a flexible and efficient power genera- tion}

People living in the $21^{\text {st }}$ century are consuming more energy than ever, and the demand for more efficient and flexible power generation sources is increasing. One example of such a flexible power generation source is a gas turbine. Today, gas turbines are sometimes used as a complement for wind and solar power when the wind is not blowing or when the sun is not shining. This is different to how they were used previously, when the turbine was more often used as the sole energy source. This new way of operating the turbine results in a increased number of start-ups and shut-downs of the turbine engine than before, where the engines instead were run over longer periods of time. In addition, to increase the efficiency of the gas turbine, the temperature within the hot-section of the turbine must be increased. In the future it is also expected that gas turbines will be fueled by biogas to a greater extent than today when non-renewable fuels such as natural gas, are more frequently used.

This new way of running the gas turbine, with an increased number of start-ups and shut-downs, higher temperatures and new fuels, leads to new demands on the materials used within the hot-sections of the turbine. The meet these demands, research closely connected to the real application is needed and therefore the research performed for this thesis has been performed in close collaboration with the turbine industry.

\subsection{Background and aims of the research project}

The majority of the work for this $\mathrm{PhD}$ thesis has been performed within the KME programme in the programme period 2010-2013. KME is a consortium for materials technology which goal is to support research towards more efficient thermal energy processes. It consists of eight industrial companies, including Elforsk [1]. Elforsk itself represents both Swedish and international energy companies. More specifically, the work has been performed as part of the KME-502 project which was finalised in April 2014. The project in question was financed to $40 \%$ by the Swedish Energy Agency through Elforsk, and $60 \%$ by Siemens Industrial Turbomachinery AB in Finspång, Sweden, which is a member of KME.

KME-502, called Fatigue of nickel-based superalloys under low-cycle fatigue and thermomechanical fatigue conditions, was a follow-up project to KME-410, and involved a strong collaboration between Linköping University and Siemens Industrial Turbomachninery AB. In KME's overall goals for the 
programme period $2010-2013$ it was stated that:

"The program will contribute to the conversion to a sustainable energy system by development of more effective energy processes."

For the KME-502 project in particular, more effective energy processes means more efficient gas turbines, and the project had two aims:

1. To improve the knowledge regarding the deformation and damage mechanisms that occur in superalloys under conditions of low-cycle fatigue (LCF) and thermomechanical fatigue (TMF).

2. To develop material models than can be used to predict the service life of superalloy components in gas turbines.

The main focus of this thesis was on the first of these, while the second was the focus of another thesis, see [2]. However, even if the KME-502 project comprised two sub-projects, there has been a close collaboration between the two. This has resulted in both parties gaining a better understanding of both microstructure mechanisms and material modelling as well as a number of published academic papers dealing with materials testing, microstructural studies and modelling all together.

\subsection{Aims and research questions of the $\mathrm{PhD}$ work}

The overall aims of the work underlying this $\mathrm{PhD}$ thesis are to study the mechanical response during TMF as well as increase knowledge about deformation and damage mechanisms that occur in single-crystal superalloys during TMF. More specifically, the following research questions (RQs) have been addressed:

RQ1: How does the mechanical response at elevated temperatures vary between different crystal orientations of single-crystal superalloys?

From the literature, it is well known that single-crystal superalloys exhibit a tension/compression asymmetry in yield strength as well as an anisotropic behaviour. The aim of this RQ is to find out how how these phenomena affect the three main crystal orientations; $\langle 001\rangle,\langle 011\rangle$ and $\langle 111\rangle$, respectively.

RQ2: How does the crystal orientation influence the TMF life for a single-crystal superalloy? 
The elastic anisotropy shown by the different crystal orientations is expected to influence the fatigue life during TMF. However, since TMF is still a rather unexplored area, this has not yet been studied which is why this RQ has been addressed.

RQ3: What are the major deformation and damage mechanisms that are triggered in single-crystal superalloys during TMF?

Even though these materials are designed to resist deformation at high temperatures and loads, several mechanisms occur within the material. This RQ seeks to provide a deeper understanding of the deformation and damage mechanisms occurring during TMF loading.

RQ4: Do the different crystal orientations exhibit different deformation mechanisms for TMF conditions?

If the previous RQ deals with deformation and damage mechanisms in general, this question seeks instead to answer the question of whether when loaded along different crystal orientations, these materials exhibit different deformation and damage mechanisms.

RQ5: What are the effects of long dwell-times during TMF cycling and do the different crystal orientations exhibit different behaviours during the dwell-times?

During TMF cycling, it is common to apply dwell-times at the maximum temperature to study the creep relaxation and therefore simulate the condition when the turbine engine is running at steady state. RQ5 addresses the question of whether the different crystal orientations behave differently during the dwell-time. This is of great importance when performing material modelling of the TMF behaviour for example.

\subsection{Scope of the PhD thesis}

As previously stated, this $\mathrm{PhD}$ thesis deals with the TMF behaviour of Nibased single-crystal superalloys, with a focus on the deformation and damage mechanisms that occur within the material. To this end, TMF testing in the laboratory as well as microstructural investigations has been performed. A number of limitations have been made during the work. The material has been supplied as testing ready specimens sent via Siemens Industrial Turbomachinery by a materials supplier, and thus casting of single-crystal specimens has not been part of the work. Further, even though the research project KME-502 has dealt with material modelling (see section 1.2) as well as 
with materials testing and microstructural studies, as previously mentioned, the modelling forms part of another thesis [2] and is not the focus here. However, Paper VI in Part II shows an example of how TMF results can be used for material modelling.

\subsection{PhD thesis outline}

This is a compilation thesis consisting of one kappa, Part I, and eight academic papers, Part II. According to the Swedish National Agency for Higher Education (Högskoleverket in Swedish), a kappa is an introductory text in which the different parts of a compilation thesis are integrated. This thesis builds upon the licentiate thesis Nickel-Based Single-Crystal Superalloys - the crystal orientation influence on high temperature properties [3], which was presented in March 2013. However, since then new work has been undertaken which is presented in this $\mathrm{PhD}$ thesis.

Part I - Background \& Theory, the kappa, consists of ten chapters and the aim of the kappa is, as stated, to give an introduction and present the background of this research area as well as to integrate the appended papers in Part II with each other. In Chapter 1, the reader is first is introduced to the research project that underlies this thesis and the aims and research questions of this $\mathrm{PhD}$ thesis are also presented. Chapters 2 and 3, provide a general description of gas turbines and the material group superalloys, respectively, and are taken directly from [3]. Chapters 4-6 reflect the background of the new work that has been performed since the licentiate thesis was presented. In Chapter 7, the experimental methods that have been used are presented, while Chapter 8 reviews and discusses the papers appended. In Chapter 8, the discussion is on a more general level compared to the discussion in each individual paper, with the aim of integrating the papers with each other. Chapter 9 presents the conclusions of this work and also discusses how the results from this work can contribute to the research community as well as the society. Finally, in Chapter 10 possible future work that can be based on this work is presented.

In Part II - Papers Included, are the eight papers. Papers I-VI have been peer-reviewed and have been published in international journals or conference proceedings. Paper VII has been submitted to an international journal while Paper VIII is still in manuscript form and is to be submitted in the near future. The papers are not arranged in the chronological order of their publication, but instead are organised by content to provide a logical sequence. Table 1 displays how the research question stated in section 1.3 are connected to each individual paper. 


\begin{tabular}{|l|l|l|l|l|l|}
\hline & RQ1 & RQ2 & RQ3 & RQ4 & RQ5 \\
\hline Paper I & & & & & \\
\hline Paper II & & & & & \\
\hline Paper III & & & & & \\
\hline Paper IV & & & & & \\
\hline Paper V & & & & & \\
\hline Paper VI & & & & & \\
\hline Paper VII & & & & & \\
\hline Paper VIII & & & & & \\
\hline
\end{tabular}

Table 1: The connections between the research questions and each individual paper. 


\section{Gas turbines}

This chapter gives a brief introduction to gas turbines and one of their most critical components; the gas turbine blade. In addition, the superalloys as a material group are presented together with a short description on how gas turbine blades in single-crystal form are cast. 


\subsection{General description}

Gas turbines are mainly used for power generation. The general idea behind a gas turbine is that it extracts mechanical energy from a hot gas stream, which is produced from combusting fuel. Gas turbines consist of three main parts: the compressor, the combustor and the turbine. In Figure 1 the Siemens gas turbine SGT-800 is shown, and the function of the gas turbine is as follows:

1. Air inlet: Air is taken in through the air inlet.

2. Compressor: The air enters the compressor. By use of compressor discs and blades, the air is compressed and its temperature is therefore increased.

3. Combustor: The compressed hot air now enters the combustor. In the combustor, the hot air is mixed with fuel, and ignited.

4. Turbine: When the hot gas is ignited, the temperature increases and the air desires to expand. Hence, the air expands through the turbine, causing a mass flow from where mechanical energy is extracted by the gas turbine blades which start to rotate.

5. Shaft: The rotating turbine blades are coupled to a shaft. The shaft transfers the mechanical work from the turbine blades to a generator, which in its turn generates electrical work.

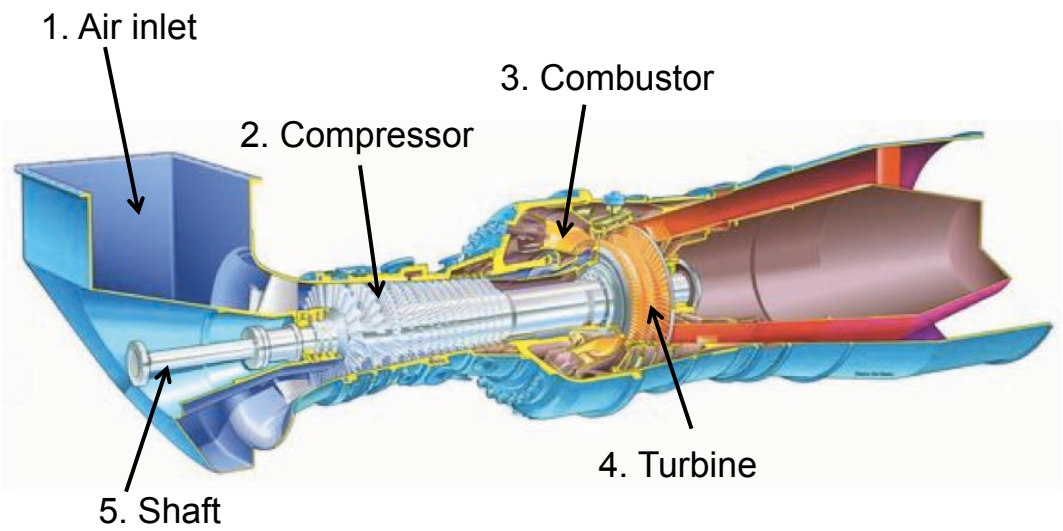

Figure 1: An SGT-800 gas turbine, which can produce $50 \mathrm{MW}$. Courtesy of Siemens Industrial Turbomachinery AB. 
It should be said that part of the mechanical work from the turbine stage is also needed to drive the compressor. Therefore, not all the energy generated by the turbine can be converted into electrical work.

The function of an aero engine is very similar to that of a landbased gas turbine. However, an aero engine works at maximum capacity only during take-off and landing, while a landbased gas turbine works at maximum capacity over longer times. Another difference between the two applications is safety. An aero engine has very high safety precautions, and here, failure of the most critical components cannot be tolerated since it can have terrible consequences. However, for a landbased gas turbine, the failure of a critical component will not have the same terrible consequences. Of course, failure in a landbased gas turbine is not desirable, but is easier to accept. This means that the components in landbased gas turbines can have much longer inspection intervals and service life than aero engine components.

\subsection{The gas turbine blade}

Gas turbine blades are positioned in the turbine stage after the combustor, see Figure 1. For a landbased gas turbine, it is common to have three or four rows of turbine blades, where each row consists of around 60-100 turbine blades. Figure 2 displays a gas turbine blade. When the hot gas expands through the turbine stage, the hot gas first hits the first row of turbine blades. All the turbine blades are shaped in such a way, that the resulting force from the hot gas stream on the blade, becomes perpendicular to the gas stream. Hence, the turbine blades start to rotate. The turbine blades are attached to a disc, which in turn is attached to the shaft. When the blades start to rotate, the disc and shaft also rotate. During service, the turbine blades rotate with a rotational speed of up to $10000 \mathrm{rpm}$ at temperatures up to $1000{ }^{\circ} \mathrm{C}$. Hence, the gas turbine blades are subjected to significant centrifugal forces and high temperatures at the same time, which put extreme requirements on the turbine blade material.

As mentioned, there are three or four rows of turbine blades in the turbine stage. The first row is subjected to the most severe conditions, since it is here the hot gas first enters and has the highest temperature. By the time the air reaches the second, third and fourth rows of turbine blades, the temperature has gradually decreased. First stage turbine blades are most commonly coated with a thermal barrier coating (TBC) to protect the blade material from the high temperature. At the same time, the blade is continuously cooled by air from the compressor. The efficiency of the gas turbine is very much dependent on the gas temperature; the higher temperature of 


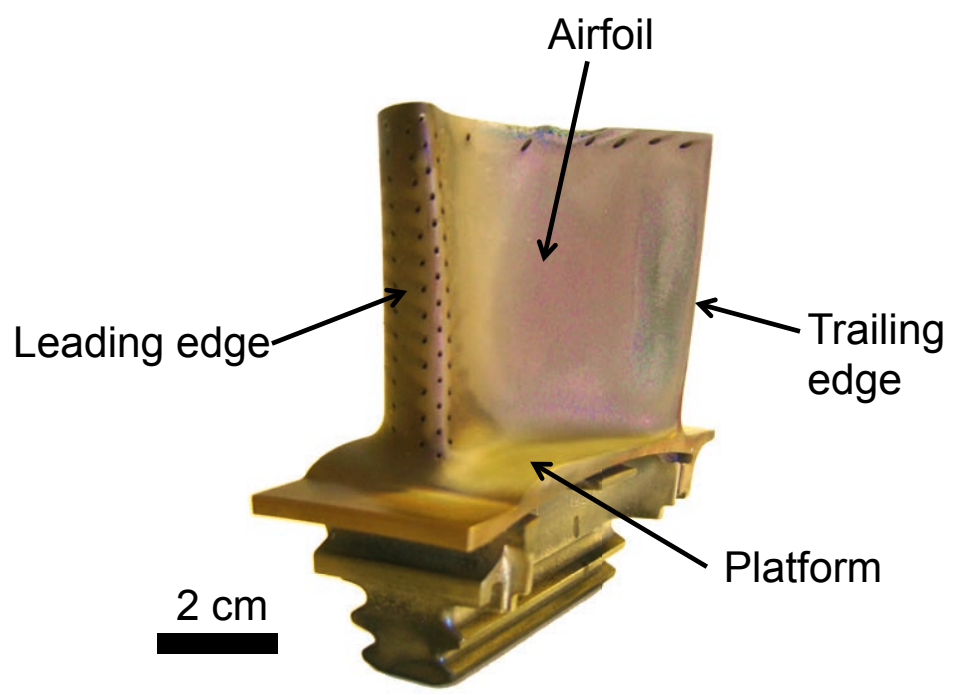

Figure 2: A gas turbine blade made from a Ni-based single-crystal superalloy. Courtesy of Siemens Industrial Turbomachinery AB.

the gas in the turbine stage the higher efficiency for the turbine. Further, the gas temperature can only be as high as what the first row turbine blades can withstand. This implies that it is on the performance of the first row of turbine blades that the whole turbine engine efficiency is determined.

\subsection{Superalloys}

Many components in gas turbines must be made from materials that can withstand both extreme temperatures and loads. As a materials group superalloys are divided into three subgroups: Ni-, Fe- and Co-based superalloys. Common to the superalloys as a group, is that they show good mechanical and chemical properties at temperatures above 0.6 times the melting temperature. Ni-based superalloys which are alloys with nickel as the primary alloying element are preferred as blade material in the previously discussed applications, rather than Co- or Fe-based superalloys. What is significant for Ni-based superalloys is their high strength, creep and corrosion resistance at high temperatures [4]. Ni is stable, i.e. it has no phase transformations, in its face centered cubic (FCC) structure from room temperature (RT) to its melting temperature at $1455^{\circ} \mathrm{C}$.

Superalloys can be used in three different forms: poly-crystal, direction- 
ally solidified (DS) or single-crystal form. Turbine disc alloys are often wrought in poly-crystal form, while it is common to cast blades in DS or single-crystal form. DS turbine blades have longitudinal grains, which are oriented parallel to the vertical direction of the blade. On the other hand, single-crystal blades consist of only one grain.

\subsection{The gas turbine blade in single-crystal form}

All turbine blades are produced through casting. Since the blades contain cooling channels that have to be obtained through casting means that they cannot be machined. Sometimes blades are cast in single-crystal or DS form rather than the more conventional poly-crystal form. Single-crystal blades are mainly used in the first row in the turbine stage, where the highest temperature is found. The casting of blades in single-crystal form is a very complicated process and is called investment casting with directional solidification. In Figure 3 a simple drawing shows how investment casting leads to a single-crystal microstructure. In the process, the superalloy material is melted in a vacuum furnace before being retracted from the furnace in a controlled direction. The front edge of the cast is cooled during the retraction. During cooling, columnar grains start to grow parallel to the direction of the retraction. By use of a grain selector, only one grain is permitted to grow any further within the component. After the grain selector, the single grain continues to grow through a pig tail shaped spiral. The spiral is followed by the actual blade form where the melt continues to solidify into one grain. After casting the bottom part, the part with columnar grains and the pig tail shaped part, is removed by machining. 


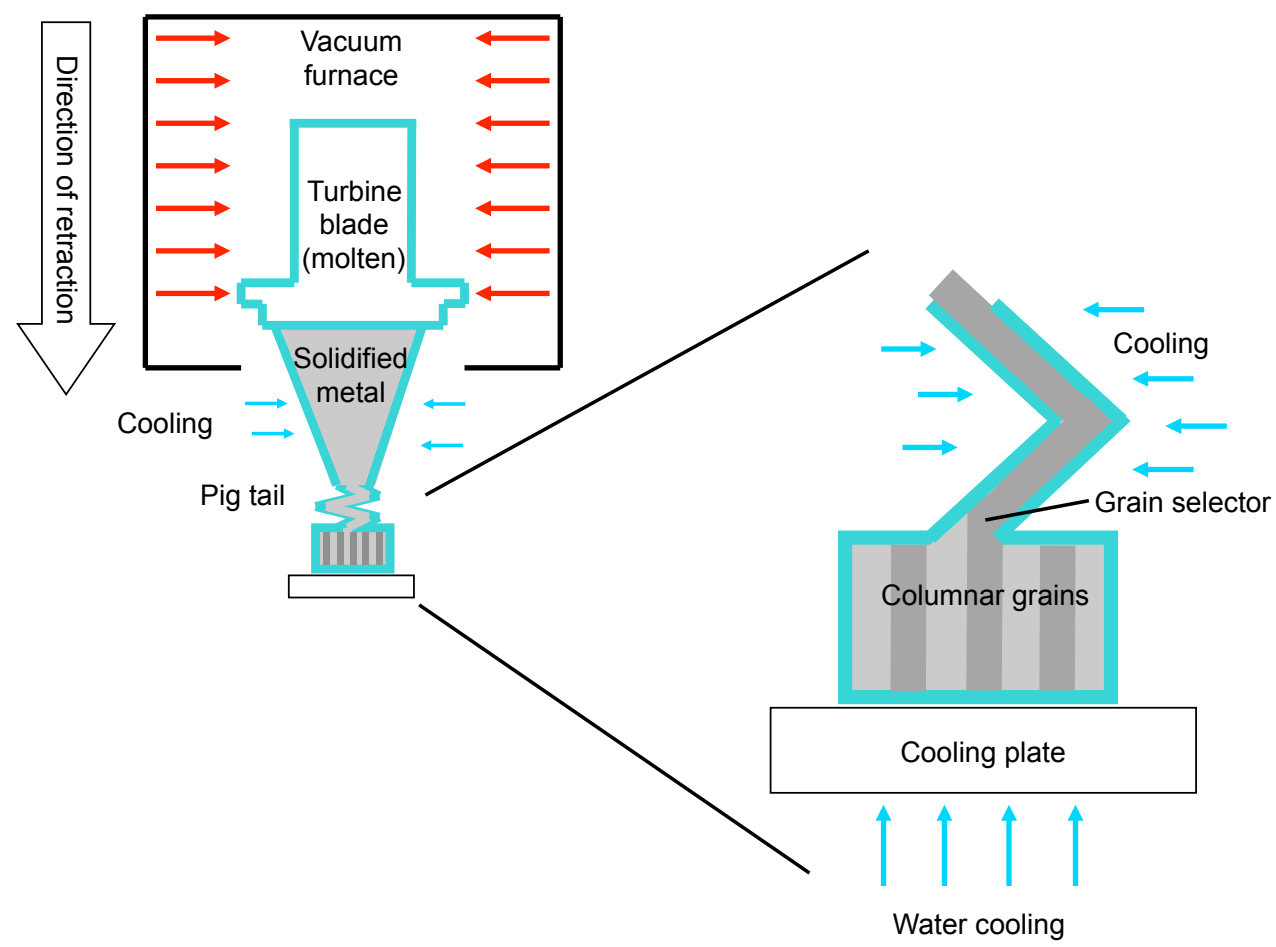

Figure 3: Investment casting with directional solidification of a turbine blade in single-crystal form. 


\section{Ni-based superalloys}

This chapter addresses the superalloys which is the material group in focus of this PhD thesis. First a general description of the superalloys is given with their composition and commonly observed phases. This is followed by a section where some remarkable properties shown by this material group are presented. 


\subsection{Single-crystal vs. poly-crystal superalloys}

It has become more common to use single-crystal rather than poly-crystal turbine blades. The reason for this can be attributed to two things: enhanced creep and fatigue properties. Good creep and fatigue properties are two of the most important factors for gas turbine blades. During creep, grain boundary sliding is a major concern. By using single-crystal instead of poly-crystal material, grain boundary sliding is avoided since no grain boundaries are present in single-crystals. Single-crystals are also anisotropic, which means that they have different properties in different directions, for example different stiffnesses in different crystallographic directions. Fatigue life is enhanced by a low Young's modulus, this since the stresses will be lower for a crystal orientation with low stiffness compared to a direction with a higher stiffness when a constant strain is considered, see Figure 4. Hence, by choosing the crystallographic direction with the lowest Young's modulus, i.e. the $\langle 001\rangle$ direction, in the upward direction of the blade, fatigue life is enhanced.



Figure 4: The anisotropic elastic behaviour shown by single-crystal materials affects the fatigue life during strain-controlled fatigue.

\subsection{Composition and phases}

\subsubsection{The typical $\gamma / \gamma^{\prime}$-microstructure}

The typical microstructure in a Ni-based superalloy is similar to a composite material with two phases, $\gamma$ and $\gamma^{\prime}$. The $\gamma$-phase works as matrix and the $\mathrm{L}_{2^{-}}$ ordered $\gamma^{\prime}$-precipitates as strengtheners [5]. Superalloys containing the $\mathrm{L}_{2}{ }^{-}$ 
ordered $\gamma^{\prime}$-precipitates surrounded by a $\gamma$-matrix, show better mechanical properties than either of the $\gamma$ - or $\gamma^{\prime}$-components themselves [6]. Figure 5 shows a typical Ni-based superalloy microstructure with the cuboidal $\gamma^{\prime}$ precipitates surrounded by the $\gamma$-matrix.

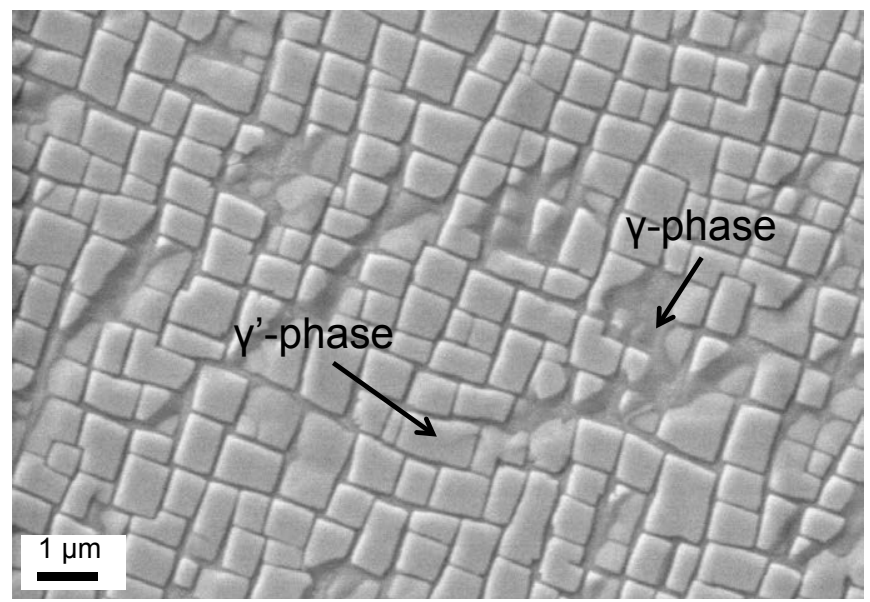

Figure 5: Scanning electron micrograph of a typical Ni-based superalloy microstructure. Cuboidal $\gamma^{\prime}$-precipitates surrounded by a $\gamma$-matrix.

The $\gamma$-phase has an FCC structure with a high fractions of $\mathrm{Co}, \mathrm{Cr}, \mathrm{Mo}$, $\mathrm{Ru}$ and Re. The $\gamma^{\prime}$-phase also has an FCC structure, and is an intermetallic compound and provides strength to the superalloy. The $\gamma^{\prime}$-cubes generally have an edge length of about $0.5 \mu \mathrm{m}$, and the size of the $\gamma$-channels surrounding the $\gamma^{\prime}$ is about $0.1 \mu \mathrm{m}$ [7]. The volume fraction of $\gamma^{\prime}$ varies among different alloys, but most commonly, the volume fraction is in the range of 60-70\%. Studies have shown that creep rupture life peaks at $\gamma^{\prime}$-volume fractions of around $65 \%$, and the effect of the $\gamma^{\prime}$-fraction on creep properties is greater on single-crystal than on poly-crystal superalloys [8, 9]. Research by Caron et al. [10] indicates that heat treatments have no effect on the $\gamma^{\prime}$-volume fraction or composition of the $\gamma^{\prime}$-precipitates. Since the $\gamma^{\prime}$-phase includes $\mathrm{Al}$, Ti and Ta, it can be expressed as $\mathrm{Ni}_{3}(\mathrm{Al}, \mathrm{Ti}, \mathrm{Ta})$. The $\gamma^{\prime}$-phase has as mentioned previously an $\mathrm{L}_{2}$-ordered crystal structure with $\mathrm{Ni}$ atoms as faces of the cube and $\mathrm{Al}, \mathrm{Ti}$ or $\mathrm{Ta}$ atoms in the corners of the cube, see Figure 6.

The properties of Ni-based superalloys are strongly dependent on the coherency between the $\gamma$ - and $\gamma^{\prime}$-phases. This coherency is quantified, and is called the lattice misfit, $\delta$. High coherency leads to a lattice misfit with a 




Figure 6: The $\mathrm{L}_{2}$-ordered crystal structure of the $\gamma^{\prime}$-phase.

small value. The lattice misfit $\delta$ is defined as

$$
\delta=2 \times \frac{a_{\gamma}-a_{\gamma^{\prime}}}{a_{\gamma}+a_{\gamma^{\prime}}}
$$

where $\mathrm{a}_{\gamma}$ and $\mathrm{a}_{\gamma^{\prime}}$ are lattice parameters for $\gamma$ and $\gamma^{\prime}$ respectively [5]. A small lattice misfit leads to a preferable microstructure and good thermal stability [11]. In addition, a small misfit leads to cubical $\gamma^{\prime}$-precipitates with sharp corners, something which is desirable for gas turbine blade components. More spherical $\gamma^{\prime}$-precipitates will increase the lattice misfit. This lattice misfit is also dependent on the temperature, and since the $\gamma^{\prime}$-phase has a lower thermal expansion than the $\gamma$-phase, the lattice misfit becomes more negative as the temperature increases.

When trying to explain the behaviour of Ni-based superalloys it is important to study how the $\gamma$ - and $\gamma^{\prime}$-phases interact with each other, as well as how different defects travel through the $\gamma$ - and $\gamma^{\prime}$-phases. Anti-phase boundaries (APB) are planar defects in the $\gamma^{\prime}$-phase and are layers of misplaced atoms. Assume that two perfect crystals of $\gamma^{\prime}$ are displaced by the vector that links the $\mathrm{Ni}$ and $\mathrm{Al}$ atoms in the ordered $\mathrm{L} 1_{2}$-arrangement, see Figure 6 . When these two perfect crystals are bonded with the displacement just mentioned, a $\mathrm{Ni}$ atom will occur on an $\mathrm{Al}$ site and vice versa, leading to $\mathrm{Ni}-\mathrm{Ni}$ and $\mathrm{Al}-\mathrm{Al}$ bonds in the structure. This creates an interface where the number of Ni-Al bonds is reduced; this interface is called an APB. An APB fault is created for example when a travelling dislocation in the $\gamma$-phase enters the $\gamma^{\prime}$-phase. This dislocation will have an energy penalty, since the closure vector needed to repair the $\gamma^{\prime}$-crystal is twice the size of the Burgers vector of the dislocation in $\gamma$. Because of this, dislocations must travel 
in pairs through the $\gamma^{\prime}$-phase, as the second dislocation removes the APB created by the first dislocation. Dislocations like these are therefore called superpartial dislocations, and one pair of superpartial dislocations is called a superdislocation.

\subsubsection{Other phases}

The precipitation of topologically close-packed (TCP) phases is very likely to be observed in Ni-based superalloys when they are subjected to high temperature and stresses, see Figure 7 . The most common TCP phases are $\sigma, \mu$ and P-phases. High amounts of $\mathrm{Cr}, \mathrm{Mo}, \mathrm{W}$ and Re promotes the formation of these TCP phases. In particular, the influence of Re on TCP formation has been of great interest for research since Re adds creep strength to the material $[12,13]$. Another study has proposed that an addition of around 2 wt. \% Ru to the alloy will reduce the TCP precipitation rate [14].



Figure 7: A backscattered electron image showing the precipitation of TCP phases within a very much deformed $\gamma / \gamma^{\prime}$-microstructure. The TCP phases appear as bright spots in the SEM image.

In Fe-Ni-based poly-crystal superalloys such as IN718, it is no longer the $\gamma^{\prime}$-phase which acts as primary strengthener. Instead, it is a body-centered tetragonal (BCT) structured phase called $\gamma^{\prime \prime}$, that primary adds strength to the material. In comparison with the $\gamma^{\prime}$-precipitates which are cuboidal, the $\gamma^{\prime \prime}$-precipitates are disc-shaped instead. The $\gamma^{\prime \prime}$-phase is a metastable phase and only provides strength to the material up to a temperature of $650{ }^{\circ} \mathrm{C}$. 
Above this temperature, the $\gamma^{\prime \prime}$-phase instead transforms into $\delta$-phase and the high strength of the material is lost. This is one reason why poly-crystal superalloys such as IN718 are used for turbine disc applications where the temperature is not as high as for turbine blades.

\subsubsection{Alloying elements}

As with all metallic materials, the alloying elements in superalloys are of great importance. The alloying elements change the lattice parameters of the $\gamma$ - and $\gamma^{\prime}$-phases, and therefore also the lattice misfit $\delta$ between the two phases, which is very important for the mechanical properties [5]. The number of alloying elements in Ni-based superalloys varies among alloys. The alloying elements are for example aluminium (Al), boron (B), carbon (C), chromium (Cr), cobalt (Co), hafnium (Hf), molybdenum (Mo), niobium $(\mathrm{Nb})$, rhenium $(\mathrm{Re})$, ruthenium $(\mathrm{Ru})$, tantalum $(\mathrm{Ta})$, titanium $(\mathrm{Ti})$, tungsten (W) and zirconium (Zr) [5]. See Table 2 for chemical compositions for some common superalloys.

\begin{tabular}{lccccccccccc} 
Alloy & Ni & Al & Co & Cr & Hf & Mo & Re & Ti & W & Si & Ta \\
\hline STAL-15 & bal. & 4.55 & 5.0 & 15.0 & 0.1 & 1.0 & - & - & 3.7 & 0.25 & 8.0 \\
CMSX-4 & bal. & 5.6 & 9.6 & 6.4 & 0.1 & 0.6 & 2.9 & 1.0 & 6.4 & - & - \\
CMSX-6 & bal. & 4.8 & 5.0 & 10.0 & 0.1 & 3.0 & - & 4.7 & - & - & 6.0 \\
CMSX-10 & bal. & 5.7 & 3.3 & 2.2 & - & 0.4 & 6.3 & 0.23 & 5.5 & - & 8.3 \\
MD2 & bal. & 5.0 & 5.1 & 8.0 & 0.1 & 2.1 & - & 1.3 & 8.1 & 0.1 & - \\
SRR99 & bal. & 5.5 & 5.0 & 8.0 & - & - & - & 2.2 & 10.0 & - & 12.0 \\
TMS-75 & bal. & 6.0 & 12.0 & 3.0 & 0.1 & 2.0 & 5.0 & - & 6.0 & - & 6.0 \\
TMS-82 & bal. & 5.3 & 7.8 & 4.9 & 0.1 & 1.9 & 2.4 & 0.5 & 8.7 & - & 6.0 \\
PWA-1480 & bal. & 5.0 & 5.0 & 10.0 & - & - & - & 1.5 & 4.0 & - & 12.0
\end{tabular}

Table 2: Nominal chemical composition in wt. \% for some commercial superalloys.

Al, Ti and Ta add strength to the alloy, since they form the strengthening $\gamma^{\prime}$-phase. Re, W and Mo add strengthening to the $\gamma$-phase through solid solution strengthening [15], and also improve the creep resistance of the alloy. Re improves the creep properties most, followed by W, Ta, Cr, Co [5]. However, too high fraction of any of these elements can result in microstructure instability, and precipitation of the undesirable TCP-phases. Moreover, the hardness of the $\gamma$-phase is increased with Re-fractions that are too great. However, the hardness of the $\gamma^{\prime}$-phase remains unchanged [16]. At isothermal conditions, an increase in Re-content results in a nonuniform oxidation [17]. 
The addition of $\mathrm{Al}, \mathrm{Cr}$ and $\mathrm{Co}$ improves resistance to oxidation, corrosion and sulphidation [4].

Several elements can be added to control the grain size and structure. For example B, C, Hf and Zr are added to form carbides and borides at the grain boundaries in poly-crystal superalloys, so-called grain-boundary strengthening. But, since no grain boundaries are present in single-crystal superalloys, the fractions of these elements are lower, or even non-existent in single-crystal superalloys [5]. The absence of these alloying elements leads to more simplified alloy chemistry and the melting temperature of the material is also increased without these elements [18]. Because of this, a single-crystal microstructure can have several advantages over a poly-crystal microstructure.

Superalloys in single-crystal form are often classified into different generations depending on their compositions:

$1^{\text {st }}$ generation: no $\mathrm{Re}$ or $\mathrm{Ru}$

$2^{\text {nd }}$ generation: approximately $3 \%$ Re and no Ru.

$3^{\text {rd }}$ generation: contains both $\mathrm{Re}$ and $\mathrm{Ru}$.

$4^{\text {th }}$ generation: contains both $\mathrm{Re}$ and $\mathrm{Ru}$.

\subsection{Some remarkable mechanical properties}

Ni-based superalloys have some remarkable properties which make them suitable for high temperature applications. The fact that the yield strength of superalloys increases with increased temperature is particular and together with the good fatigue and creep properties makes them a good choice for turbine blade material.

\subsubsection{Yield strength temperature dependence}

$\gamma^{\prime}$-hardened Ni-based superalloys have yield strengths at RT in the range of $900-1300 \mathrm{MPa}$ [15]. What is particular for these alloys is that the yield strength does not decrease with increased temperature. Instead, it is widely recognized that for several superalloys the yield stress is increased with increased temperatures up to a peak stress temperature of around $800{ }^{\circ} \mathrm{C}$ [19-22]. However, after $800{ }^{\circ} \mathrm{C}$, the yield strength decreases rapidly, and at $1200{ }^{\circ} \mathrm{C}$ the resistance to plastic deformation is small. See Figure 8 for an illustration of this behaviour. 




Figure 8: The anomalous yielding behaviour of $\mathrm{Ni}$-based superalloys.

To understand this behaviour it is important to consider the creation of Kear-Wilsdorf locks [5]. This is when superpartial dislocations cross-slip from the octahedral plane $\{111\}$ to the cube plane $\{001\}$, creating Kear-Wilsdorf locks. Assume a screw superdislocation cross-slip from the $\{111\}$ plane to the $\{001\}$ plane. The part of the dislocation which is still in the $\{111\}$ plane, cannot advance since the Peierls force on the $\{001\}$ plane is greater than the Peierls force on the $\{111\}$ plane [23]. The Peierls force is the force needed to move a dislocation in a crystal lattice [18]. In this case, the Kear-Wilsdorf locks work as microstructural locks since the cross-slipped superpartial dislocations cannot move further without pulling APBs behind them. This strengthening effect starts when the temperature is increased, and is the main reason why superalloys show increased yield strength with increased temperature. Another study showed that at temperatures below the peak stress temperature, octahedral slip dominates, while at temperatures above the peak stress temperature, cube slip is dominant instead [24]. An extensive study into yield strength temperature dependence and microstructure evolution during yielding was made for the single-crystal Ni-based superalloy SRR99 [25]. When loading at temperatures from RT to around $550^{\circ} \mathrm{C}$, both the $\gamma$ - and $\gamma^{\prime}$-phases were sheared by deformation bands. Paired dislocations from the $\gamma^{\prime}$-phase expanded, and resulted in a high dislocation density in the $\gamma$-matrix. At temperatures from $760-980{ }^{\circ} \mathrm{C}$, dislocations instead were created in the $\gamma$-matrix and became concentrated at the $\gamma / \gamma^{\prime}$-interface. The conclusion drawn from this study was that at the lower temperatures, the $\gamma^{\prime}$-phase becomes the host for dislocation expansion and the mechanical properties become dependent on the $\gamma$-matrix. Further, the $\gamma$-matrix strength is 
governed by the resolved shear stress required to push dislocations into the $\gamma^{\prime}$-precipitates and create APBs. However, at the higher temperatures, it is instead the $\gamma$-matrix which is the host of dislocation expansion, and the mechanical properties become dependent on the $\gamma^{\prime}$-phase. Finally, the $\gamma^{\prime}$-phase is dependent on the APB energy which decreases quickly with increased temperature. Due to this, the superalloy strength decreases at temperatures above $800^{\circ} \mathrm{C}$. Other dislocation mechanisms have also been proposed in the literature. One study points to six different dislocation mechanisms which may cause the peak in yield strength: abnormal plastic behaviour of the $\gamma^{\prime}$-phase, changes of the $\gamma^{\prime}$-precipitate dispersion, ternary phases, dynamic strain ageing (DSA) effects, the lattice misfit and a dislocation line in tension $[20]$.

\subsubsection{Tension/compression asymmetry}

Another remarkable property for Ni-based single-crystal superalloys is a tension/compression asymmetry. These alloys do not always follow Schmid's law for slip on individual systems [26]. This non-Schmid behaviour was first presented by Takeuchi et al. [21] in 1973. At high temperatures, slip was observed on the $\{001\}\langle 1 \overline{1} 0\rangle$ slip system, obeying the Schmid-law; however for the $\{111\}\langle 1 \overline{1} 0\rangle$ slip system, deviations from the Schmid law were observed. This was explained by the Kear and Wilsdorf model, where slip on $\{111\}\langle 1 \overline{1} 0\rangle$ is blocked by cross-slip on to $\{001\}\langle 1 \overline{1} 0\rangle$. The reason for this behaviour is the presence of an $\mathrm{L}_{2}$-ordered intermetallic compound, which in the case of Ni-based superalloys corresponds to the $\gamma^{\prime}$-precipitates. During the yielding of the $\gamma^{\prime}$-phase, the critical resolved shear stress (CRSS) on the primary slip system is dependent on load axis orientation, and whether the load is tensile or compressive. This is why Ni-based alloys show a non-Schmid behaviour.

For example, a study has shown that the Ni-based single-crystal superalloy PWA1480 shows a higher tensile yield strength compared to the compressive yield strength from RT to $750{ }^{\circ} \mathrm{C}$ [27]. This asymmetry was explained by formation of microtwins associated with a superlattice extrinsic stacking fault (SESF). The same study showed that there was no difference in yield strength tension/compression asymmetry between the superalloys CMSX-4 and TMS-75. In this case, the governing deformation mechanism, was the motion of a $/ 2\langle 110\rangle$ dislocations, which explained the absence of asymmetry. Ezz et al. [28-30] investigated the tension/compression asymmetry in yield strength for both a $\mathrm{Ni}_{3}(\mathrm{Al}, \mathrm{Nb})$ and a $\mathrm{Ni}_{3} \mathrm{Ga}$ single-crystal superalloy. The results showed a strong crystallographic orientation dependent asymmetry where the asymmetry increased with increased temperature. The CRSS on the $(111)\langle\overline{1} 01\rangle$ slip system is greater in tension than in compression in the 
case for an almost perfect $\langle 001\rangle$ single-crystal. But for crystals close to the $\langle 011\rangle-\langle\overline{1} 11\rangle$ boundary in the stereographic triangle, the CRSS is greater in compression than in tension.

The tension/compression asymmetry during LCF loading at high temperatures has also been studied [31]. An asymmetry, in which the tensile stresses were greater than the compressive stresses, were observed at conditions with high strain rates at $650{ }^{\circ} \mathrm{C}$ and $750{ }^{\circ} \mathrm{C}$. Here, the $\gamma^{\prime}$-precipitates were sheared by APB coupled dislocations. However, the opposite asymmetry, where compressive stresses greater than tensile stresses, was observed at low strain rates at $750{ }^{\circ} \mathrm{C}$ and at high strain rates at $850{ }^{\circ} \mathrm{C}$. Here the asymmetry was associated with SESF in the $\gamma^{\prime}$-precipitates. At $950{ }^{\circ} \mathrm{C}$ no tension/compression asymmetry was found during LCF.

The chemical composition of the superalloy can also influence the asymmetry. A high amount of Ta resulted in higher tensile yield strength compared to compressive yield strength at temperatures from $720-750{ }^{\circ} \mathrm{C}$ [32]. The asymmetry was explained by microtwin formation due to slip at the $\{111\}\langle 112\rangle$ system. This study also investigated the tension/compression asymmetry in creep strength, but in this case, no asymmetry was found for the superalloy with a high Ta fraction.

\subsection{The crystal orientation influence on elastic and in- elastic properties}

\subsubsection{Elasticity}

Ni-based single-crystal superalloys are highly anisotropic materials, which means that have different properties in different crystallographic directions. In single-crystal form, $\mathrm{Ni}$ is elastically anisotropic, i.e. it displays different elastic properties in different directions. The change in Young's modulus in different crystal directions will influence how the dislocations cross-slip between the planes. Poly-crystal alloys do not have this anisotropic behaviour in stiffness, since the large number of grains, which all have different crystallographic orientation, lead to a more isotropic material. The stiffness for a poly-crystal material is the average value of all grain orientation stiffnesses. Pure Ni in poly-crystal form, has a stiffness $\mathrm{E}=207 \mathrm{GPa}$, compared to $\mathrm{Ni}$ in single-crystal form which has $\mathrm{E}_{\langle 001\rangle}=125 \mathrm{GPa}, \mathrm{E}_{\langle 011\rangle}=220 \mathrm{GPa}$ and $\mathrm{E}_{\langle 111\rangle}$ $=294 \mathrm{GPa}$. Those values are for pure Ni, but Ni-based superalloys demonstrate similar stiffnesses. Elastic anisotropy due to the rafting phenomenon can also occur, and this anisotropy is increased with increased temperature. For example, studies show that the elastic anisotropy factor $E_{[100]} / E_{[001]}$ in- 
creases up to 1.010-1.025 at temperatures of $1000{ }^{\circ} \mathrm{C}$ [33]. Research also shows that the stiffness strongly decreases with increased temperature [34].

\subsubsection{Yielding behaviour}

The orientation dependence of the tension/compression asymmetry of singlecrystal superalloys is widely recognized. Materials close to $\langle 001\rangle$ in the stereographic triangle are stronger in tension than compression while materials close to the $\langle 011\rangle-\langle 111\rangle$ line are stronger in compression compared to tension [28]. Figure 9 shows the yield strengths at RT and $500^{\circ} \mathrm{C}$ for the main crystal orientations $\langle 001\rangle,\langle 011\rangle$ and $\langle 111\rangle$. The figure is taken from Paper II in this thesis, and the results are further discussed in that paper.

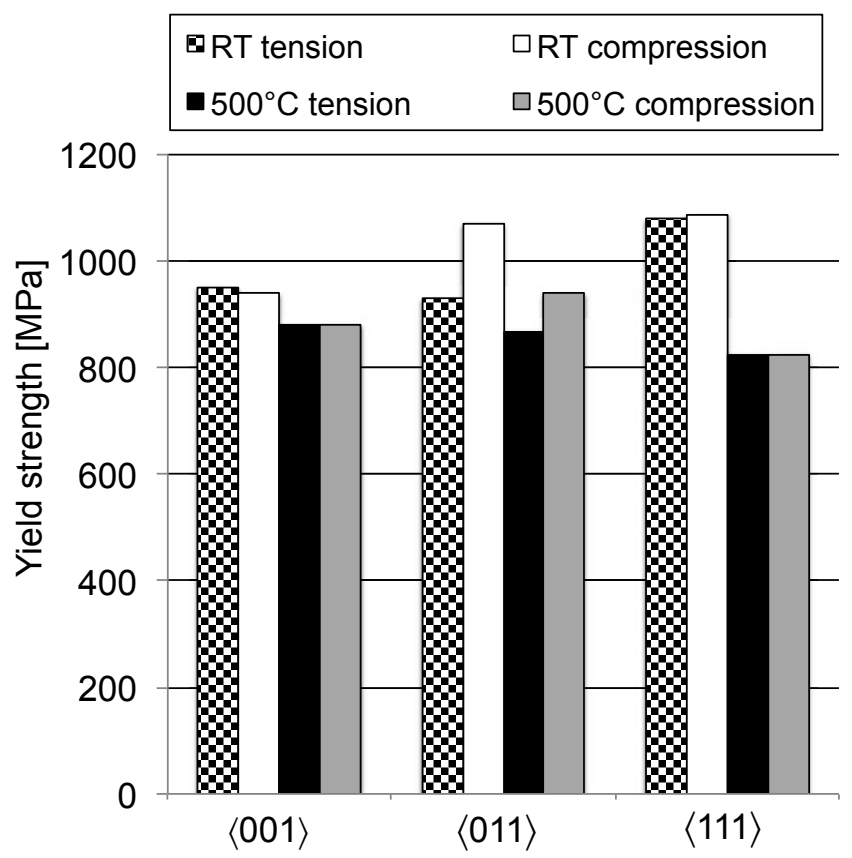

Figure 9: Yield strengths for the $\langle 001\rangle,\langle 011\rangle$ and $\langle 111\rangle$ directions at RT and $500^{\circ} \mathrm{C}$. The figure is taken from Paper $\mathrm{I}$ in this thesis with permission from the publisher.

Another difference between the crystal orientations is their behaviour during plastic deformation. Sometimes a serrated yielding is observed for superalloys, see for example [35-38]. In the literature it is common to find that 
the $\langle 011\rangle$ direction shows a serrated yielding, while the $\langle 001\rangle$ and $\langle 111\rangle$ directions show a more homogeneous yielding behaviour. The serrated yielding shown by the $\langle 011\rangle$ direction is partly attributed to the occurrence of DSA and to the fact that only one slip system is active during plastic deformation. This difference in yielding behaviour is also further discussed in more detail in Paper II in this thesis. Gabb and Miner carried out extensive work into the orientation dependence of the mechanical properties of the singlecrystal superalloy René N4 [35, 39, 40]. At RT, the yield strength of the $\langle 001\rangle$ direction was $889 \mathrm{MPa}$, while it was $830 \mathrm{MPa}$ for the $\langle 011\rangle$ direction. When the temperature was increased to $760{ }^{\circ} \mathrm{C}$, the yield strength increased for the $\langle 001\rangle$ direction, but decreased for the $\langle 011\rangle$ direction. At an even higher temperature, $980{ }^{\circ} \mathrm{C}$, there was a clear decrease in yield strength for both directions. At yielding, the $\langle 011\rangle$ direction showed a serrated yielding behaviour and in addition, loud pops were heard during deformation. The serration of the $\langle 011\rangle$ direction was explained by the fact that only one single slip system was active for this direction. A tension/compression asymmetry in yield strength was also observed. Here the $\langle 001\rangle$ direction was stronger in tension than compression. Orientations near $\langle 011\rangle$ in the stereographic triangle displayed the opposite behaviour and in such cases the yield strength was higher in compression than tension. Fatigue lives were found to be highly orientation dependent and orientations with low stiffness showed longer fatigue lives.

The hearing of loud pops during the yielding of $\langle 011\rangle$ loaded material reported by Gabb and Miner is interesting. Similar sounds were observed when coated CMSX-4 material was tested, and acoustic emission was used to measure the noise [41]. The $\langle 011\rangle$ direction generated a sound while the $\langle 001\rangle$ and $\langle 111\rangle$ directions were more quieter. Paper III in this thesis shows the same result. Here a clear sound was heard from the $\langle 011\rangle$ direction during loading into a TMF cycle.

Another study has also reported a different yielding behaviour for the $\langle 011\rangle$ direction [42]. In this case, a $\langle 011\rangle$ oriented single-crystal superalloy showed both an upper and a lower yield point and a propagation of Lüders bands, while the yield point for $\langle 001\rangle$ and $\langle 111\rangle$ was clearly marked. Deformation bands were visible on the surfaces of the specimens, and the path of the bands depended on the loading direction. 


\section{4 \\ Factors influencing the thermomechanical fatigue behaviour}

In order to understand the TMF properties of superalloys, other testing conditions have to be studied to put the TMF behaviour of superalloys into context. In this chapter, other properties, such as isothermal fatigue, creep and oxidation, which may influence the TMF behaviour, are presented. 


\subsection{Rafting}

When materials are subjected to gaseous environments and high temperatures, the microstructure is likely to degrade in a number of ways, for example by oxidation and hot corrosion [43]. Another type of degradation that is significant in the case of superalloysis rafting where the $\gamma^{\prime}$-particles are directionally coarsened and it has shown to occur in gas turbine blades during service due to the centrifugal forces at high temperatures [44]. Figure 10 shows this type of microstructure, where the $\gamma^{\prime}$-precipitates no longer have a cuboidal shape.



Figure 10: A backscattered electron image showing a rafted $\gamma / \gamma^{\prime}$-microstructure which was subjected to OP TMF $100-950{ }^{\circ} \mathrm{C}$.

Rafting is a time-dependent high temperature $\left(\approx 900{ }^{\circ} \mathrm{C}\right)$ diffusion controlled process $[7,45]$ and it is believed that the driving force of this phenomenon is to decrease the internal lattice misfit stresses [46, 47]. A decrease of the overall $\gamma / \gamma^{\prime}$ interfacial energy is attributed to both an elastic interaction between the internal stresses at the $\gamma / \gamma^{\prime}$ interface, [48], and the interaction of dislocations relaxing the lattice misfit $[49,50]$. Generally, the rafting phenomenon is connected to creep deformation at elevated temperatures, see for example [8, 33, 51-55]. According to Matan et al. [56] rafting may occur without any external loading, if a critical amount of plastic strain has been introduced in the material and that the temperature is high enough. This has also been shown by Veron et al. [57] and Leidermark et al. [58]. As mentioned, rafting is stress, time and temperature dependent, and rafting starts when superalloys are subjected to loadings at homologous temperatures up to 0.8 (homologous temperature refers to the ratio between the operating and 
melting temperatures of the material). One study shows that when CMSX-4 is subjected to $100 \mathrm{MPa}$ at $1150{ }^{\circ} \mathrm{C}$, the rafting is completed after $10 \mathrm{~h} \mathrm{[51]}$.

Rafting is either P-type or $N$-type [59]. P-type means that the rafts lie parallel to the load direction, while N-type means that the rafts lie transverse to the load direction. The orientation of the rafting is dependent on the lattice misfit. A negative misfit, which is observed in CMSX-4 and STAL-15 for example, leads to an N-type rafting if the loading is tensile, and P-type for compressive loadings. If instead the alloy has a positive lattice misfit, tensile stresses lead to a P-type rafting, while compressive stresses lead to rafting of the N-type. Figure 11 shows when a P- or N-type of rafting is created.

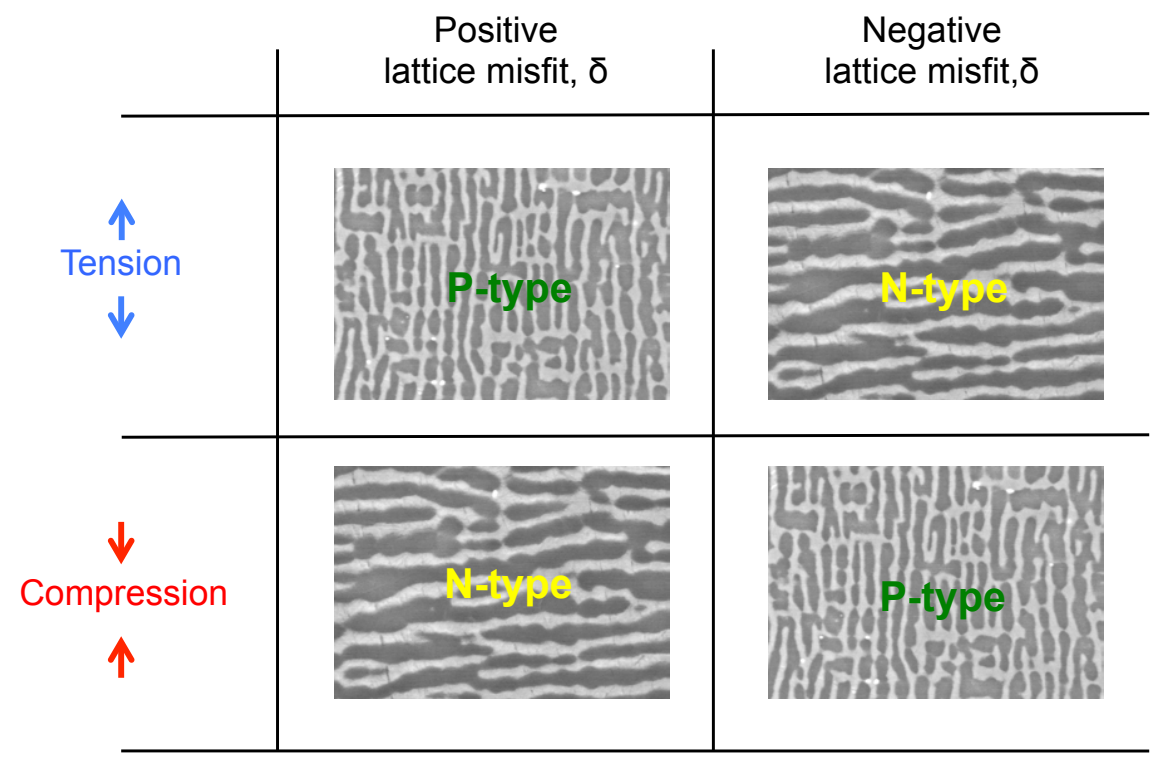

Figure 11: Whether $\mathrm{N}$ - or P-type of rafting is obtained depends on the lattice misfit between the $\gamma$ - and $\gamma^{\prime}$-phases and whether the load is tensile or compressive.

A rafting parameter was proposed by Ignat et al. [49]. This rafting parameter, $\mathrm{R}$, is equal to

$$
R=\frac{2 L^{2}}{4 L T}=\frac{L}{2 T}
$$

where $\mathrm{L}$ and $\mathrm{T}$ are the average mean linear lengths of the $\gamma^{\prime}$-precipitates in 
directions normal and parallel to the loading direction. When no rafting is observed, i.e. when the $\gamma^{\prime}$-precipitates still have a cubic form, L and T are both 1 and the rafting parameter is 0.5 .

That rafting influences the mechanical properties of superalloys is undisputable. However, whether this is in a positive or negative direction seems to depend on several factors. Pre-rafting of the material is one way to study this, and it has been shown that specimens oriented along the $\langle 001\rangle$ and $\langle 011\rangle$ directions seem to show a reduction of $25 \%$ in yield strength when a rafted structure is created prior to testing, while materials oriented along the $\langle 111\rangle$ direction showed less tendency for rafting and a less reduction of yield strength [58].

It has also been shown that the $\gamma / \gamma^{\prime}$-morphology has a great influence on the isothermal fatigue properties, see for example [60-62]. By introducing P-type rafts, the fatigue life can be enhanced compared to that obtained with cuboidal $\gamma^{\prime}$-particles. On the other hand, the introduction of N-type of rafts has a negative effect on the fatigue life, compared to having cuboidal $\gamma^{\prime}$-particles. Fatigue cracks propagate perpendicular to the load axis, and P-type rafts act as obstacles for crack propagation. N-type rafts do not stop the propagation of fatigue crack as well as P-type rafts do. According to Li et al. [63, 64], alloying with Re retards the rafting process during LCF which in their study proved to be beneficial for the fatigue life. Regarding the TMF properties, Neuner et al. [65] have shown that the pre-rafting of the microstructure seems to influence the fatigue life differently, depending on which TMF cycle is used. Further, Tetzlaff et al. [66] showed that pre-rafting improves high-temperature creep properties.

\subsection{Isothermal fatigue}

In the lower parts of the turbine blade such as the blade foot, the temperature rarely exceeds $500{ }^{\circ} \mathrm{C}$ and at this temperature, the microstructure of superalloys is fairly stable, and temperature variations from the start-up and shutdown of the engine will not influence the microstructure significantly. Still, extraordinary loads from the start-up and shut-down are prevalent which means that isothermal fatigue testing, for example LCF, has to be taken into consideration when trying to predict the behaviour of the blade foot. In section 5.3, the differences between LCF and TMF, from a gas turbine blade perspective, are taken into consideration.

Due to the anisotropic behaviour of single-crystal materials, the crystal orientation in which the material is loaded will influence the fatigue life (during strain-controlled fatigue) and orientations with a low stiffness are 
superior, see for example [39, 67, 68]. However, according to both Dalal et al. [67] and Miner et al. [39], it seems that the influence of the crystal orientation disappears when inelastic strains are considered instead of total strains. As in the case of TMF, dwell times influence the life time during LCF and results indicate that this is detrimental to the LCF life [68].

The tension/compression asymmetry which is presented in more detail in section 3.3.2, has to be considered when studying the behaviour during LCF cycling, especially from a modelling perspective. Whether tensile stresses are larger than compressive stresses or vice versa seems to be both temperature and strain rate dependent, see for example Jiao et al. [31] and Wang et al. [69]. According to [31], the reason for this behaviour is associated with $(111)\langle 112\rangle$ viscous slip, which produces superlattice intrinsic or extrensic stacking faults within the $\gamma^{\prime}$-precipitates.

The deformation and damage mechanisms occurring during LCF are well reported in the literature, see for example [70-73]. In [71], a cyclic hardening response during LCF was connected to dislocation interactions within the $\gamma$-phase, and in [70] cycling softening was explained by a rapid generation of dislocation networks at the $\gamma / \gamma^{\prime}$-interface and that rafting occurred more slowly. Further, it is certain that the temperature influences the deformation mode during LCF, and according to Hong et al. [74], during LCF tests at 750 ${ }^{\circ} \mathrm{C}$ and $850{ }^{\circ} \mathrm{C}$, crack initiation occurs at internal pores, while at $950{ }^{\circ} \mathrm{C}$, crack initiation occurs instead at the specimen surface due to high-temperature oxidation.

Generally, one may argue that the following is true for superalloys during isothermal fatigue:

Low temperatures: Stable microstructure, very little oxidation and the fatigue life is therefore determined by the deformation behaviour within the microstructure.

Intermediate temperatures: The microstructure is still fairly stable but the oxidation is now pronounced. The stable microstructure results in high stresses which may crack oxide boundaries.

High temperatures: Unstable microstructure, and stress relaxation occurs due to microstructural changes and creep, which means that oxidation is not as dominant as at an intermediate temperature.

\subsection{Creep}

Creep under static loading has for a long time been considered to be the major deformation mode for single-crystal superalloys that are considered 
suitable for blade material. According to [5], only a few per cent creep strain can be tolerated in a turbine blade before it has to be exchanged. For most materials, creep deformation can be divided into three stages; (i) primary, (ii) secondary (steady state) and (iii) tertiary creep, see Figure 12. During primary creep, the creep strain rate increases rapidly. However, when the secondary creep stage is initiated, the creep rate becomes fairly constant, and thus a steady-state is obtained. Finally, during tertiary creep, the creep strain rate once again increases rapidly before fracture occurs. However, the creep behaviour of single-crystal superalloys is different to that of polycrystal alloys since single-crystals rarely show a constant creep strain rate, i.e. secondary creep. Instead, there is a progressive increase in creep strain rate [5]. This behaviour has been demonstrated for example by $\mathrm{Yu}$ et al. [75] where creep tests at $700{ }^{\circ} \mathrm{C}$ showed a distinct primary creep stage, the secondary creep stage, or steady-state stage, occurred soon before the tertiary creep initiated and finished with failure. Creep tests at $900{ }^{\circ} \mathrm{C}$ showed a shorter primary stage almost immediately followed by a long tertiary creep during which the strain rate accelerated, and here, no steady-state stage was observed.

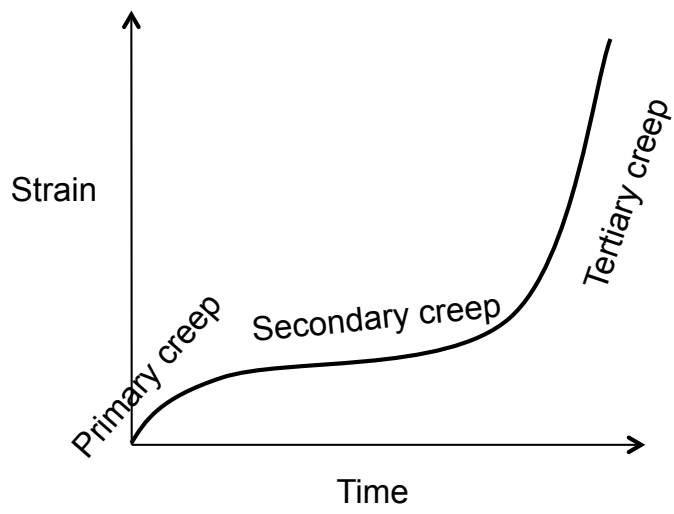

Figure 12: The three creep stages; primary, seconday and tertiary creep, respectively. Superalloys in single-crystal form rarely show any secondary creep.

Similar as in the case of fatigue properties, the creep performance of superalloys is strongly dependent on the crystal orientation in which the material is loaded, see for example [76]. Literature studies often conclude that the $\langle 011\rangle$ direction has worse creep properties than the $\langle 001\rangle$ and $\langle 111\rangle$ directions, see for example [55, 77-79]. One explanation for this is the orientation of the rafted $\gamma^{\prime}$-particles. For $\langle 011\rangle$ oriented specimens, the orientation of 
the rafting is $45^{\circ}$ from the stress axis while for $\langle 001\rangle$ oriented specimens the rafting is either parallel or perpendicular to the stress axis [55]. The $\gamma^{\prime}$-rafts oriented $45^{\circ}$ from the stress axis do not act such good obstacles for dislocation motion as the parallel or perpendicular $\gamma^{\prime}$-rafts, wherefore the $\langle 011\rangle$ direction shows less creep strength than the $\langle 001\rangle$ direction.

According to Lukas et al. [77], the tensile creep properties decrease in the sequence $\langle 111\rangle,\langle 001\rangle,\langle 011\rangle$ while in compression, the creep properties decrease in the sequence $\langle 001\rangle,\langle 111\rangle,\langle 011\rangle$. In addition, Kakehi $[78,79]$ showed that the $\langle 001\rangle$ direction has better creep properties than the $\langle 011\rangle$ direction. In that study it was found that the $\langle 001\rangle$ direction shows better properties in tension than in compression during creep at $700{ }^{\circ} \mathrm{C} / 820 \mathrm{MPa}$. In the case of the $\langle 011\rangle$ direction, it seems to be stronger in compression creep than in tensile creep, which was also shown by Courbon et al. [80]. Thus, an inverted tension/compression asymmetry was found for the $\langle 001\rangle$ and $\langle 011\rangle$ directions. The tension/compression asymmetry in creep strength was also studied by Tsuno et al. [27] for the $\langle 001\rangle$ direction where the asymmetry was attributed to twin formation during compression creep. Mechanical twins weaken the material and therefore, the $\langle 001\rangle$ direction has better creep strength in tension than in compression. They also concluded that the creep asymmetry increases with increased temperature from 750 to $900{ }^{\circ} \mathrm{C}$. Paper $\mathrm{V}$ in this thesis deals with the anisotropy as well as tension/compression asymmetry during TMF creep relaxation and the reader is referred to that paper for more information on this subject.

Generally it may be argued that the deformation during high temperature creep contains dislocation motion within the $\gamma$-phase. See Figure 13 for a STEM image of a creep tested single-crystal superalloy. According to Caron et al. [10], improved creep properties are obtained with cuboidal $\gamma^{\prime}$ precipitates with a size of $0.45 \mu \mathrm{m}$ compared to smaller and more odd-shaped precipitates. In [79], it is stated that superfine secondary $\gamma^{\prime}$-precipitates have a greater positive effect on the creep properties than the primary $\gamma^{\prime}$ precipitates. Further, it has been shown that the best creep resistance is obtained when the volume fraction of $\gamma^{\prime}$ is around $65 \%$ [8]. Creep deformation at high temperature leads to rafting of the $\gamma / \gamma^{\prime}$-microstructure and generally, the resistance to creep is improved due to this phenomenon because dislocations are prevented from climbing around the $\gamma^{\prime}$-particles and instead have to cut through the $\gamma^{\prime}$-particles [18]. More specifically, it has been shown that rafts parallel to the loading axis, obtained from pre-rafting, are beneficial to creep properties [66]. Rafting occurs rapidly; for example at $1150{ }^{\circ} \mathrm{C} / 100 \mathrm{MPa}$ the rafting has been shown to be completed already after $10 \mathrm{~h}$ [51]. During this time, the creep rate decreases with increased strain. At a critical strain of $0.7 \pm 0.3 \%$, the strain rate once again increases before 
failure is observed.

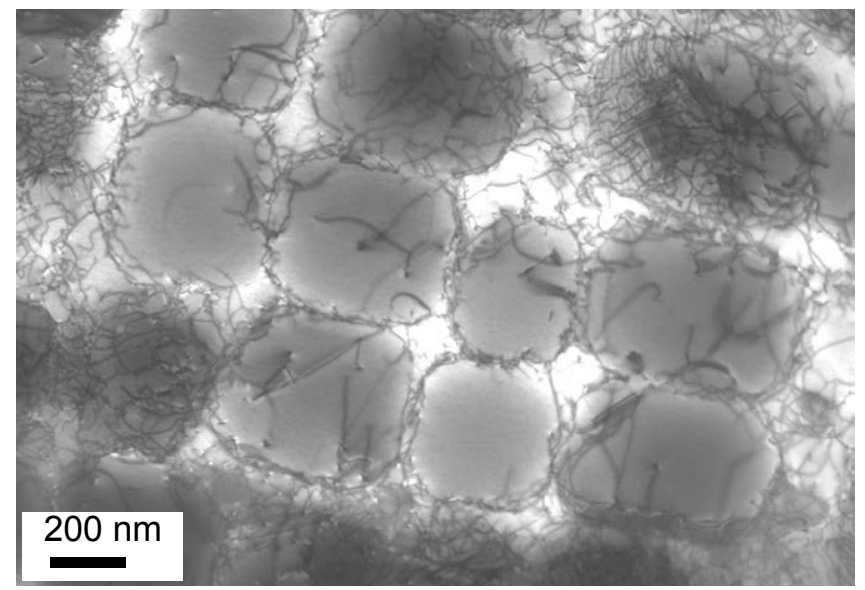

Figure 13: STEM image of creep tested STAL-15 tested at $750^{\circ} \mathrm{C}$ and $500 \mathrm{MPa}$.

As with other mechanical properties, the creep resistance is highly dependent upon the alloying elements. However, in contrast to the other mechanical properties, there is one element that strongly influences the creep properties; Re. Re contents of up to $1 \%$ increase both creep and fatigue properties, see for example [81-83]. It has also been shown that the addition of Re can increase the creep rupture life from $100 \mathrm{~h}$ to $1000 \mathrm{~h}$. This is referred to as the Re-effect [5]. One reason for the Re-effect is that diffusion is a major mechanism in the creep process, and in comparison to the other alloying elements, Re diffuses slowly in Ni. Previous studies have discussed that the Re-effect in superalloys is due to the formation of Re-clusters with a size of $1 \mathrm{~nm}$, see for example [84]. However, extensive recent research by Mottura et al. [85-87] has shown that Re clusters are unstable in Ni due to its FCC structure; therefore it is unlikely that clustering is the reason for the Re-effect. The amount of Re in superalloys has increased during the development of new alloys. In first-generation superalloys, the Re-content was zero, the second-generation had about 3 wt. \%, whilst the third-generation superalloys can contain Re-amounts up to 6 wt. \%, see section 3.2.3. Creep tests at $850{ }^{\circ} \mathrm{C}$ and $500 \mathrm{MPa}$ have shown that creep rupture lives have increased 10 times between the first and third-generation superalloys. At higher temperatures but lower loads, $1050{ }^{\circ} \mathrm{C}$ and $150 \mathrm{MPa}$, the creep rupture lives increased from $250 \mathrm{~h}$ to $1000 \mathrm{~h}$ between the generations and the most substantial difference is the amount of Re [5]. However, if the amount of Re becomes too large, formation of TCP phases can initiate, which will cause a 
deterioration of the mechanical properties of the material. The strengthening elements, such as Re and W, will then gather in the TCP phases instead of in the $\gamma$-matrix, thereby leading to a decrease in creep deformation resistance. In paper VIII in Part II of this thesis, results from creep testing of STAL15 with and without an addition of Re are presented, and it can clearly be observed that Re is beneficial for the creep properties.

It has been shown that heat treatments can improve the creep properties [10]. By heat treating the superalloy CMSX-2, aligned $0.45 \mu \mathrm{m}$ cuboidal $\gamma^{\prime}$-precipitates were achieved, which resulted in an increased creep strength. Compared to irregular $\gamma^{\prime}$-precipitates, the cuboidal $\gamma^{\prime}$-precipitates showed a homogeneous deformation, which explains the increase in creep strength. In a recent study by Steuer et al. [88] it was shown that faster solution treatment cooling rates, improves both isothermal and non-isothermal creep properties. Microstructure variations such as porosity and formation of TCP phases, have been shown to influence the creep life and therefore have to be considered when the creep life is to be predicted, see for example Le Graverend et al. [89]. Further, in [13] it is stated that stress concentrations are more easily generated in regions close to TCP phases.

Hence, creep in conjunction with TMF, is an important deformation mode in materials considered for blade material, and it is vital in the development of next-generation alloys to understand the interaction between TMF and creep .

\subsection{Oxidation}

When metals are subjected to high temperatures, oxidation and hot corrosion will occur [43], and this leads to a deterioration of mechanical properties such as the fatigue properties. Even though gas turbine blades are coated with ceramic coatings such as TBCs, the metal temperature sometimes approaches $1000{ }^{\circ} \mathrm{C}$, and at this temperature, oxidation and hot corrosion will occur at the metal surface. During oxidation, the problem is not only that the metal surface is oxidised, but in addition, the $\gamma / \gamma^{\prime}$-microstructure starts to degrade as a result. When $\gamma^{\prime}$-forming elements such as $\mathrm{Al}$ and Ti start to diffuse from the base material to form $\mathrm{Al}_{2} \mathrm{O}_{3}$ and $\mathrm{Cr}_{2} \mathrm{O}_{3}$, a $\gamma^{\prime}$-depleted zone is created close to the oxidised surface, see Figure 14. This is detrimental to the mechanical properties since these are highly dependent on the $\gamma^{\prime}$-phase. According to [5], $\mathrm{NiO}, \mathrm{Al}_{2} \mathrm{O}_{3}$ and $\mathrm{Cr}_{2} \mathrm{O}_{3}$ are the most important oxides that may form in superalloys; of these $\mathrm{Al}_{2} \mathrm{O}_{3}$ is the most stable one, followed by $\mathrm{Cr}_{2} \mathrm{O}_{3}$ and $\mathrm{NiO}$.

During TMF cycling these oxides are created at the high-temperature 
end of the cycle, and since the oxides have a low ductility, they are prone to cracking at the low-temperature end of the cycle. According to Han et al. [90], the oxidation resistance of a superalloy is a fatigue life determining factor during out-of-phase TMF in which oxidation occurs in compression and then cracks in tension at the cold end of the TMF cycle. The reader is referred to section 5.1 for further information regarding different TMF cycles. It has also been shown that oxidation plays an important role in assisting crack propagation in superalloys during TMF, see for example [91, 92].

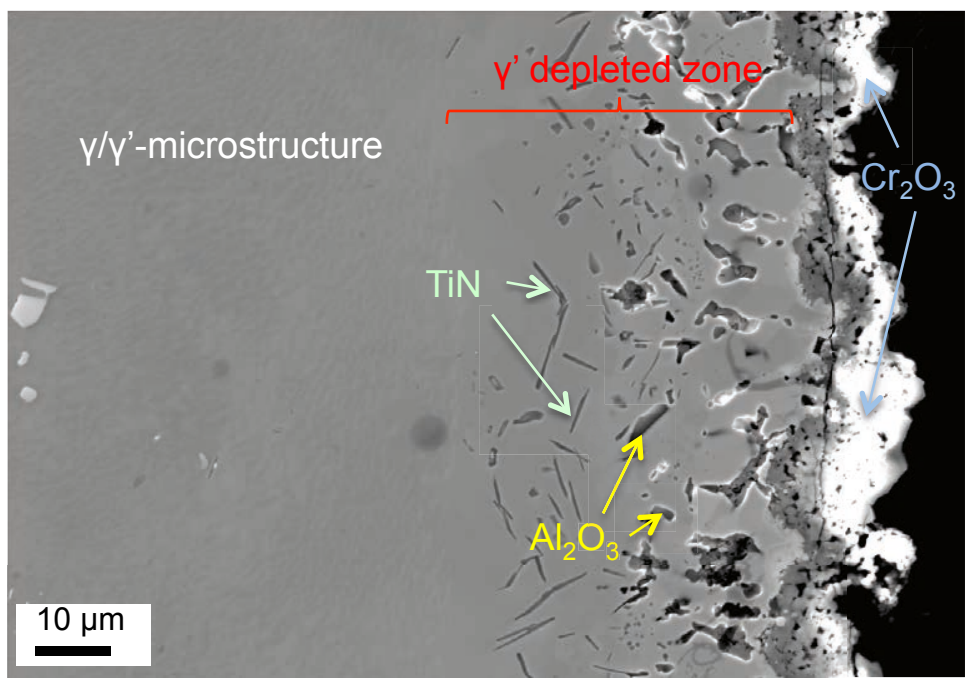

Figure 14: Oxidation layer of IN792 creep tested at $950{ }^{\circ} \mathrm{C}$ for $680 \mathrm{~h}$. Courtesy of Kang Yuan. 


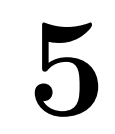

\section{Thermomechanical fatigue}

This chapter addresses the main topic of the PhD thesis; thermomechanical fatigue. The aim is to provide a broad overview of the area and therefore the chapter not only considers the topic from a gas turbine perspective but also introduces the literature in the field. 


\subsection{Thermomechanical fatigue: some general comments}

By thermomechanical fatigue (TMF) is meant cycling of both temperature and mechanical strain. From a testing perspective, the step from performing conventional isothermal fatigue tests to TMF tests is quite significant. Not only is the TMF testing procedure more complex, but a different equipment is also needed. For example, a conventional high-temperature oven cannot be used since the temperature must be cycled more rapidly than a conventional oven is capable of, and therefore both induction heating, which is possible to heat in a more rapid way, and forced cooling are often needed. There are two standards for TMF testing, see [93] for the ASTM standard and [94] for the ISO standard. In addition, there is also a Validated Code-ofPractice for Strain-Controlled Thermo-Mechanical Fatigue testing produced by a European joint research center, see [95]. For a detailed description of how the TMF tests that underlie this thesis were performed, please see section 7.2.

Different types of TMF cycles, for example in-phase (IP), out-of-phase (OP), clockwise diamond (CD) and counter-clockwise diamond (CCD), can be applied, see Figure 15. During IP TMF, creep relaxation at maximum temperature occurs in tension and plastic deformation occurs in compression at the cold end of the TMF cycle, see Figure 16 (a). On the other hand, for OP TMF, creep relaxation at maximum temperature occurs in compression and plastic deformation in tension, see Figure 16 (b). The type of TMF cycle that should be chosen is determined by the type of loading condition which needs to be studied. Please see section 5.3 for a description of how different TMF cycles can be connected to different parts of the gas turbine blade.



Figure 15: Four different TMF cycles: IP, OP, CD and CCD. 

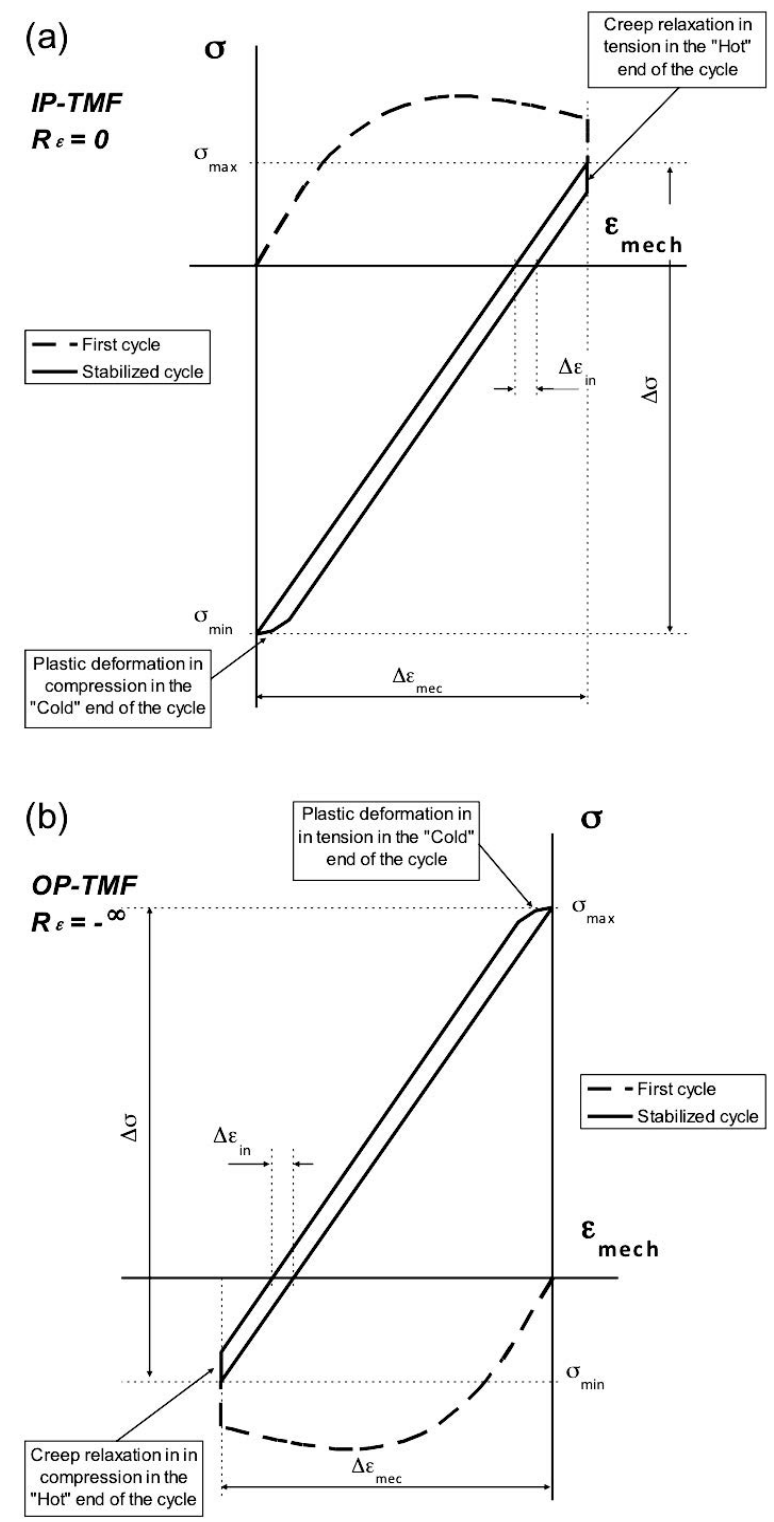

Figure 16: The hysteresis loops for a) IP TMF and b) OP TMF. The figures are taken from [102] with permission from the publisher. 


\subsection{Thermomechanical fatigue: a literature review}

Knowledge of the effects of TMF in superalloys is still limited compared to what is known about other high-temperature testing conditions such as creep and LCF, areas where a significant amount of research has been performed, see sections 4.2 and 4.3, respectively. However, over the last couple of years, research into the area of TMF has become more common and some of the results of this research are presented and discussed below. This review is limited to single-crystal superalloys and unless otherwise stated, the materials discussed are loaded along their $\langle 001\rangle$ crystallographic direction.

Han et al. [90] studied the differences between IP and OP TMF and found that OP TMF life was shorter than IP TMF life. This was explained by the fact that maximum tensile stresses which are obtained in the cold end of the TMF cycle during OP conditions, is therefore harmful for the material. During IP TMF, creep deformation was found to be dominant, while oxidation was found to cause shorter life time during OP TMF. The same study also discussed how the mean stress influences the TMF life. IP TMF cycling leads to compressive mean stresses while OP TMF leads instead to tensile mean stresses. Since compressive mean stresses hinder crack nucleation while tensile mean stresses promotes crack nucleation, IP cycling leads to better fatigue lives compared to OP TMF cycling. According to Liu et al. [96], a comparison of IP and OP TMF reveals that there is a strain range dependency. At higher strain ranges, IP TMF life was shorter than OP TMF life. However, at lower strain ranges, IP TMF life was found to be longer than OP TMF life. Due to the tension/compression asymmetry in the yield strength of single-crystal superalloys (see section 3.3.2), different deformation mechanisms were found in the IP and OP specimens, respectively. In that study, IP TMF seemed to create dislocation networks in the $\gamma / \gamma^{\prime}$-microstructure, while OP TMF lead instead to the introduction of stacking faults and shearing of the $\gamma^{\prime}$-cuboids. An example of what the dislocation activity within the $\gamma / \gamma^{\prime}$-microstructure can look like from TMF testing is shown in Figure 17. This shows that when the dislocations propagating in $\gamma$ encounter the $\gamma^{\prime}$-phase, they are sometimes hindered from further propagation and instead surround the $\gamma^{\prime}$-precipitates. However, it can also be seen from this image that some of the dislocations enter the $\gamma^{\prime}$-phase.

Recent research by $\mathrm{Yu}$ et al. [97] shows that a shorter TMF life is obtained from IP cycling than from OP. The deformation features observed were mainly dislocation bands at higher strains and dislocation networks at lower strains. During IP TMF these were mainly of $\{100\}$ type, while they were instead of $\{111\}$ type during OP TMF. The question of whether IP or OP conditions are the most detrimental for the TMF life remains open and 
has to be studied more extensively. In Paper III of this thesis, results from both IP and OP TMF tests are presented and these too show a strain range dependency for the fatigue life. At high strain ranges, IP life was longer than OP life, while at lower strain ranges the opposite was found. However, only six TMF tests were performed in that study and more testing must be done to fully confirm this finding.



Figure 17: STEM image of TMF tested STAL-15 from $100-950{ }^{\circ} \mathrm{C}$ showing the dislocation activity within the $\gamma / \gamma^{\prime}$-microstructure.

To consider how the microstructure is affected by a steady-state running of the turbine engine, dwell-times at maximum temperature are often applied during TMF testing. If the temperature during the dwell-time is high enough, rafting of the $\gamma / \gamma^{\prime}$-microstructure will occur. At the same time, the material will undergo creep relaxation, either in tension or compression, depending on the TMF cycle, see Figure 16. The amount of creep relaxation is often significantly greater during the first TMF cycle than the following cycles. Paper V discusses how dwell-times of $100 \mathrm{~h}$ during each TMF cycle influence the creep relaxation in both tension and compression of specimens oriented along different crystallographic directions. It was found that a significant tension/compression asymmetry in creep relaxation is prevalent and that the degree of asymmetry changed between the different directions. Zhang et al. [91] studied the microstructure evolution during TMF testing with a 1 $\mathrm{h}$ dwell-time and subsequently divided the TMF test into three stages: (i) primary creep relaxation where dislocations fill the $\gamma$-channels and cut the $\gamma^{\prime}$ cuboids; (ii) secondary steady state creep relaxation where the dislocations 
formed during the tensile deformation are eliminated; and (iii) tertiary creep relaxation where de-twinning of deformation twins occurs. Hirsch et al. [98] applied a superimposed high-cycle fatigue waveform during the dwell-time of the TMF cycle, and this influenced the TMF life significantly due to a change in mean stress.

The introduction of dwell-times has also been shown to influence the fracture behaviour $[92,99]$. When specimens are subjected to TMF cycling without a dwell-time in compression, the initial crack seems to grow perpendicular to the stress axis and is assisted by oxidation. When the crack reaches a deformation twin plate, it instead propagates along this twin plate. However, TMF cycling with a dwell-time in compression leads to significant plastic deformation in tension, and twins are created more rapidly, sometimes already from the second TMF cycle [91]. Subsequently, twin intersections at the specimen surface result in stress concentrations where cracks may initiate. In such cases the crack propagation starts at the twin intersections and propagates (with help from oxidation) along twin plates already from the surface. It seems that twinning during TMF cycling, is a compressive stress phenomenon rather than a tensile one, see [91, 100, 101]. According to [101], a tension/compression asymmetry of the twinning behaviour is prevalent during the intermediate stage of TMF cycling, since the force needed to create a twin in tension is significantly larger than in compression. Regarding the formation of twins in superalloys at intermediate temperatures $\left(660-700{ }^{\circ} \mathrm{C}\right)$, careful work by Kovarik et al. $[103,104]$ discusses the formation on twins on a general level and shows that twinning partial dislocations propagate through the $\mathrm{L1}_{2}$-ordered $\gamma^{\prime}$-precipitates on $\{111\}$ planes and the rate limiting process of microtwinning is re-ordering within the $\gamma^{\prime}$-phase. In addition, twinning seems to be facilitated by a low stacking fault energy [105].

Hence, the formation of deformation twins is an important mechanism during TMF, and Figure 18 illustrates this phenomenon. In (a), several parallel twins have propagated through the $\gamma / \gamma^{\prime}$-microstructure, while in (b), twins have propagated in different directions and the intersections of twins propagating in different directions seem to trigger recrystallization and the formation of TCP phases. Recrystallization is believed to be detrimental for the TMF properties, since single-crystal superalloys usually contain no grain boundary strengthening elements such as C or B. Figure 19 provides a more detailed micrograph of this behaviour and it shows very clearly that new grains and TCP phases have precipitated. This image also shows that larger twins contain smaller twins of nano-size.

Extensive research into twinning during TMF has been performed by Zhang et al. $[91,92,106,107]$. It seems that the twins may arise in the $\gamma$ matrix and afterwards propagate through the gliding of partial dislocations 
along $\{111\}$ planes. Zhang et al. also discussed, with assistance from [108, 109], that since the twins originate in the $\gamma$-phase, to improve the TMF properties it is of great importance to strengthen the $\gamma$-phase to obstruct the formation of twins. Elements such as Re and Ru partition mainly to the $\gamma$-phase, hence, the addition of those elements is believed to improve TMF properties. According to [110], deformation twins grow on $\{111\}$ planes in the area close to the crack tip at the high temperature-compression part of the OP TMF cycle. These twins later form a preferential path of crack propagation. The formation of twins may also be facilitated by micropores in the material, [111], and the size of twins seems to influence the type of fracture during TMF; a small number of thick twins results in brittle fractures while a greater number of twins instead leads to more ductile fractures, [112].
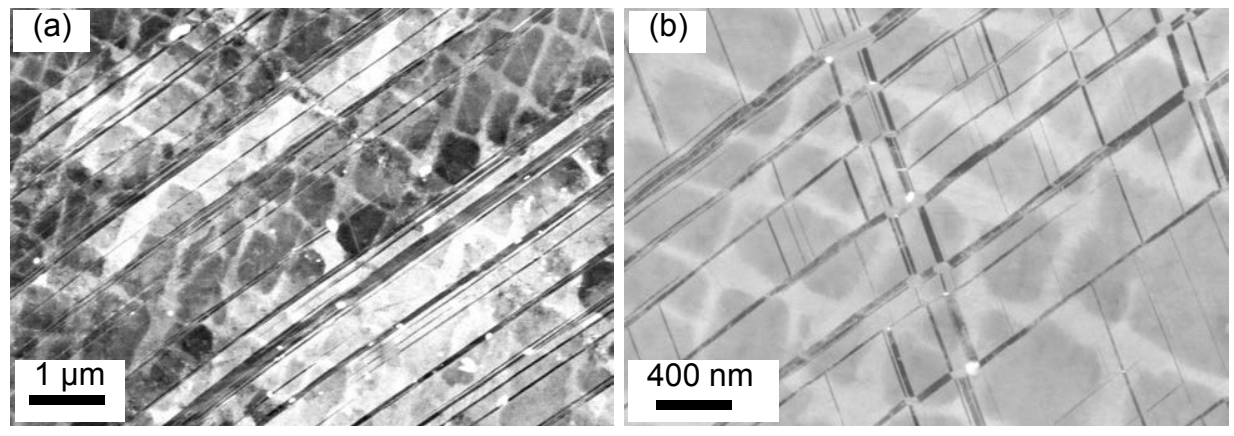

Figure 18: Deformation twins from OP TMF cycling $100-750{ }^{\circ} \mathrm{C}$, (a) parallel twins propagating through the $\gamma / \gamma^{\prime}$-microstructure and (b) twins propagating in different directions where the intersection of twins seems to initiate recrystallization and formation of TCP phases (bright spots).

That deformation twinning is a major deformation mechanism during TMF cycling was also shown by Moverare et al. [113] who performed OP TMF from $100-1000{ }^{\circ} \mathrm{C}$ of the CMSX-4 alloy. In that case, the twins extended along the whole cross-section of the specimens, and it was found that even though cracks propagated along twins plates, crack initiation was a surface phenomenon. Another study found that TMF failure occurs along recrystallized deformation bands and that the recrystallization process is facilitated by oxidation [114]. Hence the processes of deformation twinning and recrystallization are important mechanisms when designing for good TMF properties.

Heat treatments can influence the TMF behaviour for Ni-based single- 


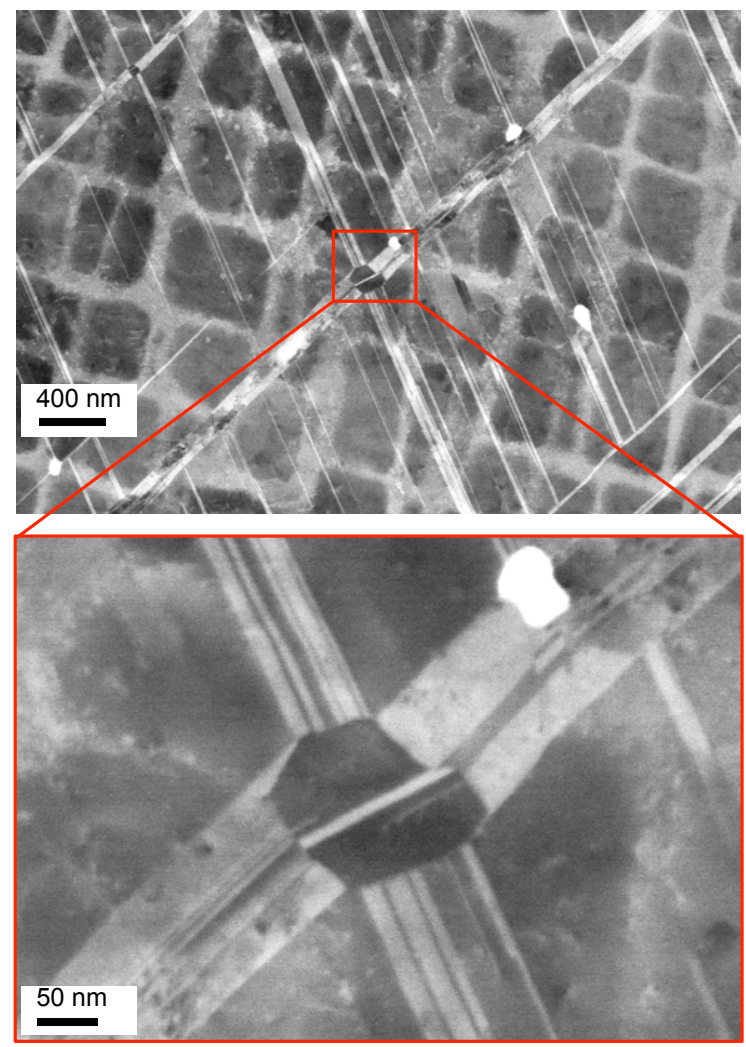

Figure 19: Recrystallisation and formation of TCP phases at twin intersections from OP TMF cycling $100-750{ }^{\circ} \mathrm{C}$.

crystal superalloys [113]. OP TMF testing from $100-1000{ }^{\circ} \mathrm{C}$ on virgin and aged materials, respectively, showed that twinning was the major deformation mechanism for both conditions. However, for virgin material, the deformation was more localized and the twins propagated through the whole specimen, leading to crystallographic fractures along one of the $\{111\}$ planes. For aged material on the other hand, the deformation was less localized. In such cases, the twins were hindered by the precipitation of TCP phases, leading to an increased cyclic ductility and necking. The role of TCP phase precipitation on TMF life cannot be disregarded. In Figure 19, is can be seen that TCP phases have precipitated at twin intersections. The intermetallic TCP phases are partly introduced into the material due to large amounts of $\mathrm{Cr}, \mathrm{Mo}, \mathrm{W}$ and Re [5]. In the case of the aged material in above mentioned 
study, it was shown that the precipitation of TCP phases will deplete the microstructure of strengthening elements such as Re and W and that will decrease the material's resistance to creep relaxation.

\subsection{Thermomechanical fatigue from a gas turbine per- spective}

During the start-up of the turbine engine, the turbine blades begin to rotate, and the temperature within the hot section increases, while during shutdown, the temperature instead decreases. This means that the temperature is not constant during start-up and shut-down and the stress state in the blade is therefore greatly affected by temperature gradients. To take those temperature gradients into account, TMF testing must be considered instead of the more traditional isothermal fatigue testing where the strain is cycled at a constant temperature, for example LCF. The importance of understanding the influence from the temperature cycling cannot be underestimated. It has, for example, been shown that the OP TMF life is only half that of LCF [115]. As mentioned, to simulate the condition when the engine is running at steady-state, a dwell-time at maximum temperature is commonly applied.

Still, LCF testing is very important, and it is possible to compare LCF and TMF conditions from a turbine blade perspective. On the blade foot, the temperature seldom reaches temperatures above $500{ }^{\circ} \mathrm{C}$ and up to this temperature, the microstructure is fairly stable, and thus the temperature cycling will not influence the material properties significantly, see Figure 20. Hence, to simulate blade foot conditions, to perform LCF is sufficient. On the other hand, the temperature on the blade platform and airfoil is in a temperature range from 500 to $1000{ }^{\circ} \mathrm{C}$ and at these temperatures the microstructure is no longer stable. Therefore, to fully understand the properties of the whole turbine blade, both LCF and TMF must be considered.

As previously stated, the temperature on a real component is not uniform while the engine is in service. In fact, damage can often be co-related to so called hot- or cold-spots on the blade. A hot-spot is an area where the temperature is locally very high compared to its surroundings. This spot wants to expand through thermal expansion but is prevented from doing so due to its cooler surroundings. Hence, stress state within a hot-spot is compressive rather than tensile. On the other hand, cold spots are areas where the temperature is locally low compared to their surroundings and here, tensile stresses are obtained instead. Both the above mentioned conditions can be simlulated in the laboratory by either IP or OP TMF, see Figures 15 and 


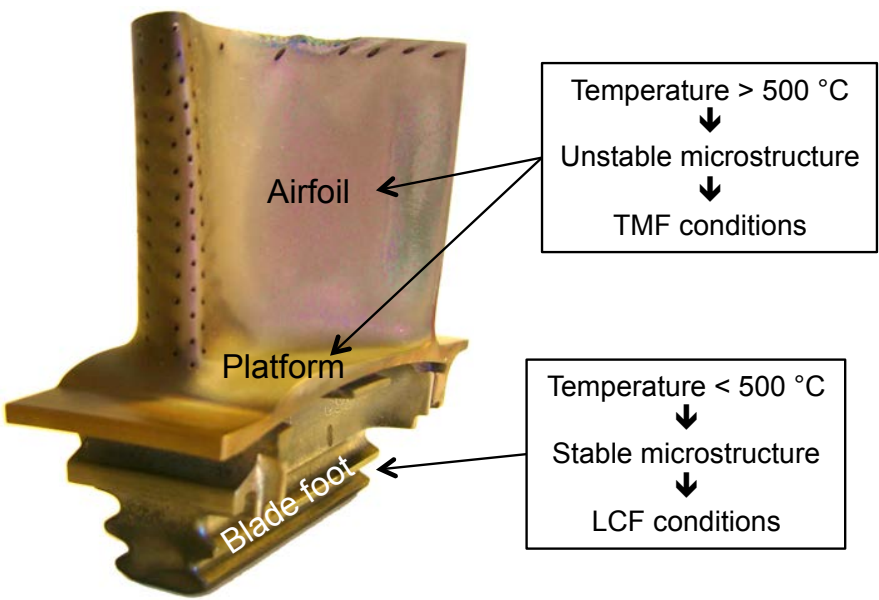

Figure 20: LCF and TMF tests simulate different parts on the gas turbine blade.

16. During IP TMF, high temperature creep relaxation in tension and low temperature plastic deformation in compression will occur, and thus leading to a typical cold-spot on the turbine blade. On the other hand, during OP $\mathrm{TMF}$, high temperature creep relaxation in compression and low temperature plastic deformation in tension will occur, i.e., a typical a hot-spot on the blade. It is more common to perform OP rather than of IP TMF testing, since TMF damage in gas turbine blades is often localised to hot-spots rather than to cold-spots. Other types of TMF cycles, for example the CD and CCD cycles, instead simulate transient effects due to the different heating and cooling rates of the thin and thick sections in a blade that occur during the start-up and shut-down of a turbine engine [102].

The occurrence of hot and cold-spots on turbine blades is also one reason why most TMF tests are performed in strain control rather than stress control. Take for example a hot-spot, which desires to expand by thermal expansion but is prevented from this by its cooler surroundings. This means that the conditions within the hot-spot are therefore in strain control rather than stress control. When performning strain controlled fatigue, materials with a low stiffness along the loading direction perform better than materials with a higher stiffness, because a lower stress will be obtained for the material with a lower stiffness at a constant strain, see Figure 4 in section 3.1. Since the elastic stiffness of a material is a function of the temperature, the stiffness will change during the TMF cycle. Figure 21 shows how the stiffness varies during a TMF test from $100-850{ }^{\circ} \mathrm{C}$. Consider for example 
an OP TMF cycle. Here the higher stiffness is obtained at the tensile part of the cycle. While for an IP cycle, the higher stiffness is obtained at the compressive part.

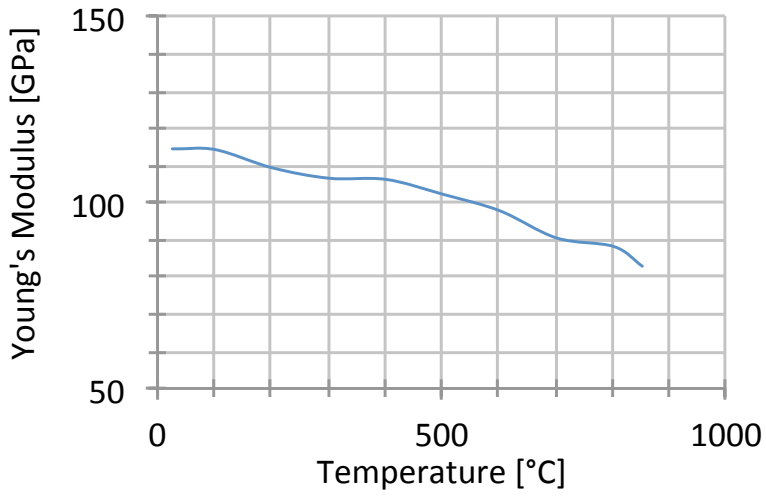

Figure 21: The change of elastic stiffness during a TMF test from $100-850{ }^{\circ} \mathrm{C}$. 



\section{6 STAL-15 - a new superalloy}

In this chapter the Ni-based superalloy STAL-15 is introduced. STAL is an acronym for Siemens Turbine Alloy or Svenska Turbinfabriks AB Ljungström, and 15 is the Cr-content. STAL-15 was developed by Siemens Industrial Turbomachinery, and during the work for this PhD thesis, this is an alloy that has been the focus of a number of studies. It is for this reason it has been given a separate chapter in the thesis. 


\subsection{General information}

STAL-15 is a relatively new Ni-based superalloy developed by Siemens Industrial Turbomachinery AB in Finspång, Sweden, and is covered by the patent shown in [116]. In this thesis, STAL-15 is the subject of both Papers VII and VIII. Table 3 displays the chemical composition of STAL-15 and for a detailed description of the alloy development history of this alloy the reader is referred to [117]. It should be noted that during its development, the alloy was first called SCA425 and later SCA425+, before being named STAL-15, and there are some small differences in chemical compositions between these forms.

\begin{tabular}{lrrrrrrrr} 
& $\mathrm{Ni}$ & $\mathrm{Al}$ & $\mathrm{Co}$ & $\mathrm{Cr}$ & $\mathrm{Hf}$ & $\mathrm{Mo}$ & $\mathrm{Ta}$ & $\mathrm{Si}$ \\
\hline STAL-15 & bal. & 4.5 & 4.9 & 15.6 & 0.1 & 1.0 & 8.1 & 0.25
\end{tabular}

Table 3: Chemical composition in wt. \% for STAL-15.

The microstructure of STAL-15 is similar to other superalloys with strengthening $\gamma^{\prime}$-precipitates in a matrix of $\gamma$, see Figure 22. The $\gamma^{\prime}$ volume fraction is around $48 \%$ of which the majority are present as cuboidals with a size of approximately $0.4 \mu \mathrm{m}$. In addition, smaller $\gamma^{\prime}$-precipitates are observed within the $\gamma$-channels.



Figure 22: A backscattered electron micrograph of virgin STAL-15. 


\subsection{Properties}

Previously, the development of superalloys has been driven by the aero engine industry and the alloys have been designed to achieve good properties from an aero engine perspective. However, as mentioned previously in this thesis, even though aero engines and industrial gas turbines are very similar, they are run in different ways, which means that slightly different properties are needed for the two types of applications. One aim behind the development of STAL-15 has been to achieve good corrosion and oxidation properties, and thus high $\mathrm{Cr}$ and $\mathrm{Al}$ contents are needed, and it has also been shown that STAL-15 is an $\mathrm{Al}_{2} \mathrm{O}_{3}$ former $[117,118]$. The other aim was to combine good TMF properties with sufficient creep properties. This means that it should have creep properties comparable to IN792, which is poly-crystalline superalloy. According to [117] it can be argued that the excellent creep properties shown for example by CMSX-4, are now unnecessary for industrial gas turbine blades due to the introduction of advanced cooling techniques. However, the introduction of advanced cooling techniques lead to more stress and temperature gradients within the material which increase the demand for excellent TMF properties, and in [117], it was shown that the TMF life of STAL-15 is comparable to that of CMSX-4.

Originally STAL-15 was designed without any Re to lower the cost and enhance the castability of the alloy. The absence of Re is also one reason why STAL-15 is less creep resistant than Re-containing alloys such as CMSX-4. Paper VIII of this thesis discusses the effects of alloying STAL-15 with Si or Re. It was found that an addition of $0.25 \mathrm{wt}$. \% Si increases the TMF by a factor of 2 . In other studies, it has been shown that the addition of $\mathrm{Si}$ influences the formation of detrimental TCP phases during high temperature exposure, see [117]. However, it seems that the addition of 0.25 wt. \% Si results in an acceptable level of TCP phases. The addition of Re improves the creep properties but it does not have the same effect on the TMF life as Si. For more information regarding the results from this study, please see Paper VIII.

The information about STAL-15 provided in this chapter concerns the single-crystal version, but the alloy in question also exists in poly-crystal form. However, since the main focus of this thesis is on single-crystal material, the reader is referred to other literature for more information regarding the poly-crystalline version of STAL-15, see for example [119]. 



\section{Experimental work}

This chapter addresses the experimental work that has been performed during the work leading to this PhD thesis. It should be noted that mechanical testing has been performed at both Linköping University and Siemens Industrial Turbomachinery in Finspaing, Sweden. However, the sample preparation and microstructure investigations were conducted at Linköping University. The exception is the atom probe analysis in Paper VIII which was performed by researchers at Oxford University in the U.K., and therefore this procedure is not included in this chapter. 


\subsection{Material}

The material used in this project has been supplied as "testing-ready" specimens by a materials supplier via Siemens Industrial Turbomachinery. Hence, casting single-crystal material and specimen production have not been included in the project. At the materials supplier, the Ni-based single-crystal superalloys specimens were produced by investment casting (see section 2.4 for a short description of this process) before they were solution heat treated to obtain the characteristic $\gamma / \gamma^{\prime}$-microstructure. Specimens oriented along the different crystal orientations were tested and their deviation from ideal crystal orientation was measured by x-ray diffraction at the materials supplier. The reader is referred to each individual paper for information regarding which alloy, heat treatments, and crystal orientations have been tested in each study, respectively.

\subsection{Thermomechanical fatigue testing}

The TMF tests performed at Linköping University were conducted in a servohydraulic TMF machine from Instron, and all the tests were performed in strain control. Induction heating and forced air cooling were used to cycle the temperature. Thermo-couples were spot-welded onto the specimens to control the actual specimen temperature. See Figure 23 for the complete TMF setup.

When performing testing, it is the mechanical strain, $\epsilon_{\text {mech }}$, that is of interest. Therefore, during the TMF testing, compensation for the thermal strain induced in the material by the temperature was made. When temperatures around $950{ }^{\circ} \mathrm{C}$ are applied, the thermal strain is about $1 \%$ for superalloys. Hence, the thermal strain is sometimes almost at the level of the desired mechanical strain. This shows the importance of compensating for the thermal strain during TMF testing. The thermal strain, $\epsilon_{t h}$, is measured by running one TMF cycle in which only the temperature is cycled, before starting the real test. To obtain the actual mechanical strain, $\epsilon_{\text {mech }}$, the thermal strain $\epsilon_{t h}$ is subsequently subtracted from the total strain, $\epsilon_{t o t}$, as follows:

$$
\epsilon_{\text {mech }}=\epsilon_{\text {tot }}-\epsilon_{t h}=\epsilon_{\text {tot }}-\alpha\left(T-T_{0}\right)
$$

where $\alpha$ is the thermal expansion coefficient of the material, $\mathrm{T}$ is the test temperature and $\mathrm{T}_{0}$ is the reference temperature at the beginning of the test. 


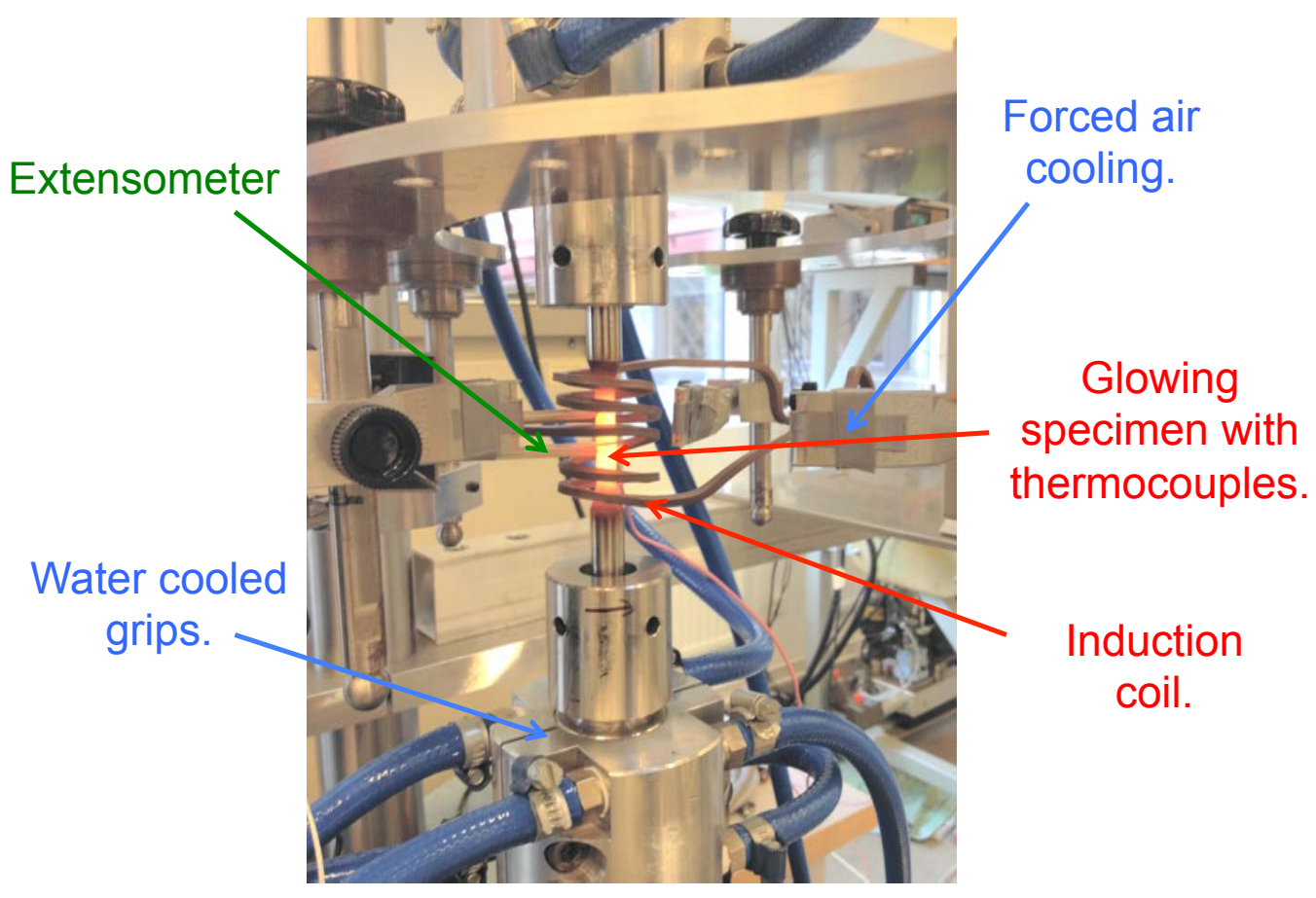

Figure 23: Complete TMF setup with a glowing specimen.

\subsection{Stereomicroscopy}

All specimens were investigated by stereo microscopy after mechanical testing. One aim of using stereo microscopy is to investigate the type of fracture that has occurred, if fracture has indeed occurred. It has also been shown that slip steps and crystallographic deformation bands on the specimen surfaces parallel to crystallographic fractures are often detectable, and stereo microscopy is a good instrument for documenting the appearance of such deformation.

\subsection{Scanning electron microscopy}

The specimens considered for scanning electron microscopy (SEM) investigation were cut parallel or perpendicular to the loading direction. To study the virgin microstructure of each specimen, a reference sample was also cut from 
the very end of the specimen. All the samples were prepared by grinding and mechanical polishing using a Struer grinding and polishing machine. SiC grinding papers from \#500 to \#4000 were used before mechanical polishing using grains from 3 to $1 / 4 \mu \mathrm{m}$. As the last step, chemical polishing was performed. For the work in this thesis, no samples were etched. The microstructure investigations that followed were performed in Hitachi SU70 FEG-SEM, where acceleration voltages from 10 to $20 \mathrm{kV}$ were used. When orientation imaging microscopy was required, an electron back-scattering diffraction (EBSD) system by HKL technology was used.

\subsection{Scanning transmission electron microscopy}

Discs intended for scanning transmission electron microscopy (STEM) investigation were first cut perpendicular to the loading direction. They were then subjected to mechanical grinding to obtain a thickness of approximately 150 $\mu \mathrm{m}$ before being punched to a diameter of $3 \mathrm{~mm}$. Subsequently, the samples were polished electrochemically using an A2 electrolyte to obtain the hole needed for this type of investigation. 


\section{Review and discussion of papers included}

In this chapter, the eight papers which are included in Part II are briefly introduced and discussed. The aim of the general discussion provided here is to integrate the different papers with each other and to answer the research questions (RQs) stated in section 1.3. Please note that the papers are not presented in the chronological order of their publication. The sequence of the papers has instead been determined by their content, in an attempt to create a logical structure. 
Paper I: Crystallographic orientation influence on the serrated yielding behavior of a single-crystal superalloy

Conditions: Tension and compression tests at $500{ }^{\circ} \mathrm{C}$ of the single-crystal superalloy MD2. Specimens oriented along the $\langle 001\rangle,\langle 011\rangle$ and $\langle 111\rangle$ crystallographic orientations, respectively, are considered.

RQ addressed: RQ1

Not only do the Ni-based single-crystal superalloys show an anisotropic behaviour, they also show tension/compression asymmetry in yield strength, see section 3.3.2. Therefore, this first paper studies the mechanical response from tension and compression tests at $500{ }^{\circ} \mathrm{C}$ on specimens loaded along different crystallographic directions. The greatest tension/compression asymmetry in yield strength is shown by the $\langle 011\rangle$ direction, where the yield strength is $70 \mathrm{MPa}$ higher in compression than in tension at this temperature. The $\langle 001\rangle$ and $\langle 111\rangle$ directions show no significant asymmetry in yield strength at this temperature.

In addition to the tension/compression asymmetry of $\langle 011\rangle$ oriented specimens, a serrated yielding behaviour is displayed by these specimens. The yielding of the $\langle 001\rangle$ and $\langle 111\rangle$ directions is more stable at this temperature. In the literature, a serrated yielding behaviour is sometimes attributed to the appearance of dynamic strain ageing (DSA) within the material, in which solute atoms interact with moving dislocations. The $\langle 011\rangle$ direction also show deformation bands, both on the specimen surfaces and within the $\gamma / \gamma^{\prime}$-microstructure, and it is believed that DSA has occurred within these deformation bands where a high dislocation density is expected. Another reason for the serrated yielding behaviour is attributed to the number of active slip systems during deformation. From the literature, is it well known that for FCC structures, the $\langle 011\rangle$ direction has four equivalent slip systems. This can be compared with eight for the $\langle 001\rangle$ direction and six for the $\langle 111\rangle$ direction. Hence, there is a higher tendency for single-slip when loading in the $\langle 011\rangle$ direction than in both the $\langle 001\rangle$ and $\langle 111\rangle$ directions. If only one slip system is active, the dislocations can only propagate in one direction, which may lead to the dislocation sometimes being stopped. When several slip systems are active instead, there is always one system in which the dislocations may propagate, and where a more homogeneous yielding can be expected in such case.

Thus, this study shows that there seems to be significant differences between the different crystallographic directions regarding both the tension/compression asymmetry and yielding behaviours. 
Paper II: Low-cycle fatigue behaviour of a Ni-based singlecrystal superalloy

Conditions: LCF tests at $500{ }^{\circ} \mathrm{C}$ of the single-crystal superalloy MD2. Specimens oriented along the $\langle 001\rangle,\langle 011\rangle$ and $\langle 111\rangle$ crystallographic orientations respectively, are considered.

RQ addressed: RQ1

As a continuation to the work described in Paper I, the same material and same crystallographic directions were subjected to $\mathrm{LCF}$ at $500{ }^{\circ} \mathrm{C}$. As expected when equivalent strain ranges are compared, the $\langle 001\rangle$ direction showed the best fatigue properties followed by the $\langle 011\rangle$ and $\langle 111\rangle$ directions. The reason for this is that specimens with lower elastic stiffness perform better during strain-controlled fatigue. Once again, the $\langle 011\rangle$ direction shows a serrated yielding behaviour in both tension and compression when loading into the LCF cycles. For this direction, a serrated yielding was observed during the first 15-20 LCF cycles, before a more homogeneous yielding initiated. As in the previous study, the occurrence of DSA as well as single-slip are believed to be reasons for the serrated yielding behaviour. A tension/compression asymmetry in mid-life stresses were observed for all crystal orientations, with the highest degree of asymmetry being found for the $\langle 011\rangle$ direction. Thus, the tension/compression asymmetry in yield strength at $500{ }^{\circ} \mathrm{C}$ shown by this direction in Paper I, is repeated during LCF cycling at the same temperature. A comparison between cyclic and monotonic stress-strain curves demonstrates that the $\langle 011\rangle$ and $\langle 111\rangle$ directions display cyclic hardening during LCF, while instead the $\langle 001\rangle$ exhibits cyclic softening. From these LCF tests, no significant differences in deformation and damage mechanisms can be observed in the microstructure.

Generally from Papers I and II it can be concluded that at a temperature of $500{ }^{\circ} \mathrm{C}$ the $\gamma / \gamma^{\prime}$-microstructure is still fairly stable and no degradation, for example rafting, occurs.

Paper III: In- and out-of-phase thermomechanical fatigue of a Ni-based single-crystal superalloy

Conditions: IP and OP TMF from $100-750{ }^{\circ} \mathrm{C}$ of the single-crystal superalloy MD2. Specimens oriented along the $\langle 001\rangle$ and $\langle 011\rangle$ directions are considered.

RQs addressed: RQ1, RQ2, RQ3 and RQ4

If Papers I and II deal with the yielding and LCF behaviours of different 
crystallographic directions, this is the first in which the main topic of this thesis is studied, i.e. the TMF behaviour of superalloys. More specifically, the difference between IP and OP TMF is investigated as well as the deformation and damage mechanisms occurring during TMF. For the $\langle 001\rangle$ direction, the difference in TMF life between IP and OP TMF loading seems to be strain range dependent, and OP leads to a longer fatigue life at a low strain range. However, at higher strain ranges, IP cycling results in a longer fatigue life for this direction. No significant differences in deformation and damage mechanisms can be detected, which can explain this strain range dependency. For the $\langle 011\rangle$ direction, only one test for each condition was performed which makes it difficult to derive any substantial conclusion from this. As in the case of the tension and compression tests in Paper I and LCF tests in Paper II, the $\langle 011\rangle$ direction shows a serrated yielding behaviour. This time it occurs during loading into the TMF cycles and it occurs during both IP and OP conditions.

Deformation twinning is found to be a major deformation mechanism in this study. The twins propagate in different directions, and at twin intersections, recrystallization and formation of topologically close-packed (TCP) phases occurs. Recrystallization in these materials is certainly deleterious for the TMF properties since single-crystal materials are seldom alloyed with any of the grain-boundary strengthening elements, such as carbon or boron. This means that grain boundaries can be considered as weak points, a finding which is confirmed since damage is visible in areas with twin intersections and recrystallization. The twinning phenomenon is more pronounced during OP conditions for the $\langle 001\rangle$ direction, while it is more obvious during IP conditions for the $\langle 011\rangle$ direction. The reason why the prominence to twinning of the two directions differ, whether they undergo IP or OP TMF, has to be further studied.

Paper IV: Deformation and damage mechanisms during thermomechanical fatigue of a single-crystal superalloy in the $\langle 001\rangle$ and $\langle 011\rangle$ directions

Conditions: OP TMF from $100-850{ }^{\circ} \mathrm{C}$ of the single-crystal superalloy CMSX-4 with specimens oriented along the $\langle 001\rangle$ and $\langle 011\rangle$ directions, respectively.

RQs addressed: RQ1, RQ2, RQ3 and RQ4

In a way that is similar to that shown in LCF, materials loaded along their $\langle 001\rangle$ directions, exhibit a higher number of cycles to failure compared 
to the $\langle 011\rangle$ direction when equivalent strain ranges are compared. In this study, high mechanical strain ranges lead to crystallographic fractures along one of the $\{111\}$ crystallographic planes, while low strain ranges instead lead to non-crystallographic fractures. This holds for both the $\langle 001\rangle$ and $\langle 011\rangle$ directions. Sometimes recrystallization occurred in areas with heavy plastic deformation, and specimens with random fractures show recrystallization close to the fracture surface. The deformation is found to be localised for both directions, and twinning is once again a major deformation mechanism for most specimens. The formation of TCP phases is seen to occur in localised deformed areas. In addition, this investigation indicates that crack propagation is a consequence of recrystallization and not vice versa. Since $850{ }^{\circ} \mathrm{C}$ is quite a high temperature, mechanical damage such as twinning and shearing has a major influence on the TMF life, while oxidation has only a minor influence.

An interesting result from this study is that the peak stress at half life for the $\langle 011\rangle$ direction decreases up to 600 cycles to failure, but then increases. This behaviour is attributed to a change in the deformation mechanism from shearing to twinning when going from high to low strain ranges of this direction. Hence, here a difference in deformation and damage mechanisms between the $\langle 001\rangle$ and $\langle 011\rangle$ directions is found.

\section{Paper V: Creep and stress relaxation anisotropy of a single- crystal superalloy}

Conditions: IP and OP TMF tests from $100-750{ }^{\circ} \mathrm{C}$ and $100-950{ }^{\circ} \mathrm{C}$, respectively, in which a $100 \mathrm{~h}$ dwell-time was applied during each cycle. In addition, creep tests at $750{ }^{\circ} \mathrm{C}$ and $950{ }^{\circ} \mathrm{C}$ at different stress levels were performed. The single-crystal superalloy MD2 with specimens oriented along the $\langle 001\rangle,\langle 011\rangle$ and $\langle 111\rangle$ directions are considered.

RQs addressed: RQ1, RQ2 and RQ5

One of the aims of this study was to investigate dwell-time creep rates during TMF cycling and to compare these to creep rates from conventional constant load creep tests. Results show that the creep rates, which for example, are needed when performing material modelling, agree well between these two types of tests. This may be beneficial since to perform TMF stress relaxation tests is more time efficient than conventional constant load creep tests. From this study it is also shown that TMF cycling seems to influence the creep rates temporarily.

Further, the creep relaxation behaviour during the TMF dwell-time is 
found to be highly anisotropic and the $\langle 001\rangle$ direction shows slightly better properties than the $\langle 011\rangle$ direction at $750{ }^{\circ} \mathrm{C}$, while the worst properties are shown by the $\langle 111\rangle$ direction. The tension/compression asymmetry previously discussed is shown to be also prevalent during TMF stress relaxation, where the greatest asymmetry is found for the $\langle 001\rangle$ direction at $750{ }^{\circ} \mathrm{C}$. Here, the creep rates in compression are some of ten times higher than to the creep rates in tension. The creation of deformation twins in compression is believed to be the reason for the higher creep rates in compression, since these weaken the material. The tension/compression asymmetry is also shown to be more significant during stress relaxation at $750{ }^{\circ} \mathrm{C}$ than $950{ }^{\circ} \mathrm{C}$.

From the conventional constant load creep tests, the $\langle 011\rangle$ direction displays poor creep ductility and also crystallographic fractures along one of the $\{111\}$ planes. This resulted in a short time to rupture in the constant load creep tests of these specimens, even if the creep rates in the TMF stress relaxation tests are comparable to the other directions.

Paper VI: Modelling of thermomechanical fatigue stress relaxation in a single-crystal nickel-base superalloy

Conditions: Modelling of the stress relaxation during the $100 \mathrm{~h}$ dwell-times of the TMF tests from Paper $\mathrm{V}$ is considered.

RQ addressed: RQ5

As stated in section 1.4, material modelling is not the focus of this thesis. However, as a continuation on Paper V and to show how TMF results can be used in an finite element context, the work presented in Paper VI is included here. In this study, the TMF stress relaxation behaviour from Paper $\mathrm{V}$ is modelled by a simple crystallographic creep model, based on Norton's creep law, together with a crystal plasticity model. The model takes both the anisotropic behaviour, as well as the tension/compression asymmetry into consideration. A good agreement is found between the TMF stress relaxation predicted by the model and the experimental results.

Paper VII: Influence of crystal orientation on the thermomechanical fatigue behaviour in a single-crystal superalloy

Conditions: OP TMF from $100-850{ }^{\circ} \mathrm{C}$ of STAL-15 with specimens oriented along different crystal orientations.

RQs addressed: RQ2, RQ3 and RQ4. 
In Papers III and IV, TMF tests of specimens oriented along different crystallographic directions were performed and the fatigue life was found to be highly orientation-dependent and orientations with a low elastic stiffness perform better. During LCF, it has been shown that when the differences in elastic stiffness are compensated, the difference in fatigue life between materials with different stiffness disappears, see for example [67]. One of the aims of the work underlying this paper, is to study if this is also holds for TMF conditions. Results indicate that factors other than the elastic stiffness may influence the TMF life. Even if the elastic stiffness is found to be the strongest factor in determining the TMF life, this study shows that the number of active slip systems that are active during deformation also influence the fatigue life during TMF. A higher number of active slip systems lead to a more widespread deformation, which is beneficial for the TMF life. On the other hand, when only one slip system is active, the deformation becomes more concentrated, which seems to be detrimental for the material's TMF properties.

This is also the first paper of this thesis in which the new alloy STAL15 is considered. See Chapter 6 for more information regarding this alloy. It is found that one major deformation mechanism of STAL-15 during OP TMF at this temperature is the creation of deformation bands with smeared and elongated $\gamma^{\prime}$-precipitates. In addition, deformation twinning is found to be a deformation mechanism as it is for MD2 described in Paper III and CMSX-4 in Paper IV. It is believed that the creation of twins is a more favourable deformation mechanism than the smeared and elongated $\gamma^{\prime}$-precipitates, when a long TMF life is the aim. During twinning, the $\gamma^{\prime}$ phase keep their cuboidal shape and the strength of the material is kept. However, when the $\gamma^{\prime}$-precipitates are smeared and elongated, they lose their strength.

Paper VIII: Thermal-mechanical fatigue behaviour of a new single-crystal superalloy: Effects of Si and Re alloying

Conditions: OP TMF from $100-950{ }^{\circ} \mathrm{C}$ and creep tests at $750{ }^{\circ} \mathrm{C}$ and 850 ${ }^{\circ} \mathrm{C}$ of three different versions of STAL- 15 .

RQ addressed: RQ3

The influence on the TMF properties from alloying STAL-15 with Si or Re is studied, and it is found that the addition of Si increases the OP TMF life by a factor of two. Re also improves the TMF properties but not to the same extent as Si. The Si-effect on the TMF life is attributed to the 
increased yield strength at low temperature, and to the fact that thinner localised deformation bands are created when $\mathrm{Si}$ is added compared to the thicker bands created without the addition of Si. Also a more crystallographic type deformation prevails in the microstructure when $\mathrm{Si}$ is added which is believed to be beneficial for the TMF life. Creep tests indicate that the previously presented Re-effect on superalloys, see section 4.3, also is prevalent for STAL-15. The addition of Re improves creep properties more than Si does. However, the improved creep properties are not directly transferred to TMF properties meaning that different mechanisms are important during TMF and creep, respectively. From this study, as well as from Papers III and IV, recrystallization along deformation bands is shown to be detrimental for the TMF life, and the ability to resist deformation along the localised deformation bands seems to be of great importance. The addition of Si seems to increase the materials resistance to recrystallization along these deformation bands. 


\section{9 \\ Conclusions and contribution}

In this chapter the conclusions drawn from the work that underlies this PhD thesis are presented. In addition, the question of how these conclusions may contribute to the research community and industry respectively is addressed. 


\subsection{Conclusions}

The focus of this thesis is on the TMF properties of Ni-based single-crystal superalloys and the mechanical response from TMF cycling as well as the deformation and damage mechanisms that occur in single-crystal superalloys are investigated.

It is found that the deformation during TMF cycling of single-crystal superalloys is often localised to several deformation bands. Along these bands, recrystallization sometimes occurs followed by crack initiation and propagation (RQ3). Moreover, twinning is a major deformation mechanism during OP TMF, here the intersection of twins seems to trigger recrystallization. In addition, the formation of TCP phases occurs at these intersections. The formation of TCP phases is often discussed as something that is detrimental for the mechanical properties of superalloys since these phases drain the $\gamma$-phase from the strengthening elements which are needed to obtain good resistance to creep relaxation during the TMF dwell-times. Hence, the formation of localised deformation bands and recrystallization along these bands together with the formation of twins are important phenomena to understand when aiming to create superalloys with a good TMF resistance (RQ3).

This work also shows a strong Si-effect on the TMF life when this element is added to STAL-15. The reason for the improved TMF properties is attributed to the fact that Si increases the yield strength at low temperatures and that thinner deformation bands are created compared to when no $\mathrm{Si}$ is added. Si also seems to promote a more crystallographic type of deformation which seems to be more beneficial when aiming for a long TMF life compared to deformation bands with sheared and elongated $\gamma^{\prime}$-precipitates.

In addition, results indicate that when single-crystal superalloys are loaded along different crystallographic directions during TMF, different deformation mechanisms may occur (RQ4). For example, in one of the studies, twinning is the major deformation mechanism for the $\langle 001\rangle$ direction, but for the $\langle 011\rangle$ direction, the major mechanism changes from twinning to shearing in the $\gamma / \gamma^{\prime}$-microstructure when going from low to high strain ranges (RQ4).

For the mechanical response during TMF cycling, results show that the elastic stiffness of the crystal orientation in which the material is loaded, is the strongest factor determining the TMF life (RQ1, RQ2). However, results indicate that the number of active slip systems during deformation is also a factor. A higher number of active slip systems during TMF, such as for the $\langle 001\rangle$ direction, results in a widespread deformation which leads to a longer TMF life. On the other hand, when a lower number of slip systems are active, for example shown by the $\langle 011\rangle$ direction, this leads to a more concentrated deformation which seems to be detrimental to the TMF life. 
Further, the $\langle 011\rangle$ direction shows a serrated yielding behaviour from both tension and compression tests as well as from LCF and TMF cycling. There might be several reasons for the yielding behaviour, for example the occurrence of DSA, but once again, the number of slip systems is believed to play a major role. When several slip systems are active, there is always one system where dislocation glide may occur during plastic deformation, and the yielding thus becomes more stable. However, with fewer active slip systems, the dislocations are sometimes stopped, which may lead to a serrated yielding.

By performing TMF tests with $100 \mathrm{~h}$ dwell-times during each cycle, it is shown that TMF cycling seems to influence the creep rates temporarily (RQ5). Further, creep rates similar to those obtained from conventional constant load creep tests, can be obtained from these kinds of TMF tests. Creep rates are needed for example when performing material modelling of the TMF behaviour, and if these can be obtained in a way which is more time efficient, it is very useful. The same study shows that the $\langle 001\rangle$ direction exhibits a significant tension/compression asymmetry during TMF stress relaxation at $750{ }^{\circ} \mathrm{C}$. Here, the creep rate is about 10 times higher in compression than in tension. The reason for this is believed to be the formation of twins during dwell-times in compression. Both the $\langle 011\rangle$ and $\langle 111\rangle$ directions show less asymmetry during TMF stress relaxation. The tension/compression asymmetry is also studied during tension and compression tests and during LCF cycling, and the greatest asymmetry is also observed for the $\langle 011\rangle$ direction. Thus, it seems that the crystal orientation that is most inclined to show a tension/compression asymmetry, is highly dependent on the loading condition.

\subsection{Contribution}

The research presented in this $\mathrm{PhD}$ thesis concerns the TMF properties of single-crystal superalloys and the contribution from this work to the research society is on both a general and specific level. TMF testing is a relatively new testing procedure and the amount of research published within this area is still rather limited. That the interest for TMF research is growing both from academia and industry is notable, since requests for TMF testing seem to be increase from both. This work, therefore contributes to our general knowledge regarding the procedure of TMF testing, the testing of superalloys in particular but also of other materials. From another point of view, this work provides the research community with specific knowledge regarding the deformation and damage mechanisms that occur during the TMF cycling of single-crystal superalloys. In addition, only a limited number of papers have 
been published that discuss the influence from the orientation of the singlecrystal on the TMF properties, and therefore this work certainly makes a contribution to the field.

In the Swedish Higher Education Act (Högskoleförordningen in Swedish) it states: "The mandate of higher education institutions shall include third stream activities and the provision of information about their activities, as well as ensuring that benefit is derived from their research findings." Thus, it is every researcher's responsibility to motivate how his/her research can contribute not only to the research community but also to the society in general. The research presented in this $\mathrm{PhD}$ thesis concerns with materials that are used in applications for power generation, such in gas turbines, and has been partly financed by the Swedish Energy Agency. As has been stated, gas turbines are more frequently used as a complement to renewable energy sources, such as when the wind is not blowing or when the sun is not shining. TMF testing is one way to simulate the conditions in which a turbine is used as a complement, rather than the main power generating source, and this this research certainly is important in way to a greener energy production. 
10

\section{Suggestions for further research}

This last chapter of Part I of this PhD thesis, addresses the topic of future work that can be done on the basis of this work. 
Since our knowledge of the TMF behaviour of single-crystal superalloys is still rather limited, a lot of work remains to be done within this area. The work on which this $\mathrm{PhD}$ thesis is based shows that the deformation from TMF is highly localised to several deformation bands. Since crack initiation and propagation are preferred to these bands, it is of great importance to understand the reason for this localised deformation in order to further improve the TMF properties of superalloys. Deformation twinning is shown to be a major deformation mechanism and thus the creation of twins is also one area which has to be further studied in the search for TMF resistant superalloys.

As this work reports on TMF tests which have been performed in the laboratory, the next step could be to compare the mechanisms reported in this work with those mechanisms observed in service-exposed turbine blade components. Do the deformation and damage mechanisms, such as the localised deformation bands and twinning, also occur in real components?

STAL-15 was developed to exhibit excellent TMF properties, and to study in more detail the deformation and damage mechanisms from TMF that occur in this alloy would also be an interesting continuation of this work.

An area where there exists an interest both from industry and academia is TMF crack growth in superalloys. The service life of critical components, such as the gas turbine blade, relies on a stable and controllable crack propagation. However, this is a rather unexplored area, and to measure how a crack grows during TMF is a very complex testing procedure. Therefore all today's models, which try to predict the crack growth, are very conservative and include large safety factors. In the gas turbine industry, to study TMF crack growth is one important step for trying to predict TMF failures in critical components. 


\section{Bibliography}

[1] KME homepage (http://www.elforsk.se/Programomraden/ElVarme/KME/), September 2014.

[2] D. Leidermark, Crystal plasticity and crack initiation in a single-crystal nickel-base superalloy. Modelling, evaluation and applications. $\mathrm{PhD}$ thesis, Linköping University, 2011.

[3] M. Segersäll, Nickel-based single-crystal superalloys - the crystal orientation influence on high temperature properties. Licentiate thesis, Linköping University, 2013.

[4] R. C. Reed, T. Tao, and N. Warnken, "Alloys-By-Design: Application to nickel-based single crystal superalloys," Acta Materialia, vol. 57, no. 19, pp. 5898-5913, 2009.

[5] R. C. Reed, The Superalloys - Fundamentals and Applications. Cambridge University Press, 2006.

[6] F. R. N. Nabarro and H. L. de Villiers, Physics of Creep and CreepResistant Alloys. Taylor \& Francis, 1st ed., 1995.

[7] H. Mughrabi, "Microstructural aspects of high temperature deformation of monocrystalline nickel base superalloys: Some open problems," Materials Science and Technology, vol. 25, no. 2, pp. 191-204, 2009.

[8] T. Murakumo, T. Kobayashi, Y. Koizumi, and H. Harada, "Creep behaviour of Ni-base single-crystal superalloys with various $\gamma^{\prime}$ volume fraction," Acta Materialia, vol. 52, no. 12, pp. 3737-3744, 2004.

[9] Y. Ro, Y. Koizumi, and H. Harada, "High temperature tensile properties of a series of nickel-base superalloys on a $\gamma / \gamma^{\prime}$ tie line," Materials Science and Engineering: A, vol. 223, no. 1-2, pp. 59-63, 1997. 
[10] P. Caron and T. Khan, "Improvement of creep strength in a nickelbase single-crystal superalloy by heat treatment," Materials Science and Engineering, vol. 61, no. 2, pp. 173-184, 1983.

[11] R. A. Ricks, A. J. Porter, and R. C. Ecob, "The growth of $\gamma^{\prime}$ precipitates in nickel-base superalloys," Acta Metallurgica, vol. 31, no. 1, pp. 43-53, 1983.

[12] C. M. F. Rae and R. C. Reed, "The precipitation of topologically close-packed phases in rhenium-containing superalloys," Acta Materialia, vol. 49, no. 19, pp. 4113-4125, 2001.

[13] T. Sugui, W. Minggang, L. Tang, Q. Benjiang, and X. Jun, "Influence of TCP phase and its morphology on creep properties of singelcrystal nickel-based superalloys," Materials Science and Engineering A, vol. 527, pp. 5444-5451, 2010.

[14] A. Sato, H. Harada, T. Yokokawa, T. Murakumo, Y. Koizumi, T. Kobayashi, and H. Imai, "The effects of ruthenium on the phase stability of fourth generation Ni-base single-crystal superalloy," Scripta Materialia, vol. 54, pp. 1679-1684, 2006.

[15] T. M. Pollock and S. Tin, "Nickel-based superalloys for advanced turbine engines: Chemistry, microstructure, and properties," Journal of Propulsion and Power, vol. 22, no. 2, pp. 361-374, 2006.

[16] K. Durst and M. Göken, "Micromechanical characterisation of the influence of rhenium on the mechanical properties in nickel-base superalloys," Materials Science and Engineering A, vol. 387-389, pp. 312-316, 2004.

[17] L. Huang, X. F. Sun, H. R. Guan, and Z. Q. Hu, "Effect of rhenium addition on isothermal oxidation behavior of single-crystal Ni-based superalloy," Surface and Coatings Technology, vol. 200, no. 24, pp. 68636870, 2006.

[18] R. W. Herzberg, Deformation and Fracture Mechanics of Engineering Materials. John Wiley \& Sons, Inc., 4th ed., 1996.

[19] R. A. Mulford and D. P. Pope, "The yield stress of $\mathrm{Ni}_{3}(\mathrm{Al}, \mathrm{W})$," Acta Metallurgica, vol. 21, no. 10, pp. 1375-1380, 1973.

[20] E. Nembach, "The high temperature peak of the yield strength of $\gamma^{\prime}$-strengthened superalloys," Materials Science and Engineering: A, vol. 429, no. 1-2, pp. 277-286, 2006. 
[21] S. Takeuchi and E. Kuramoto, "Temperature and orientation dependence of the yield stress in $\mathrm{Ni}_{3} \mathrm{Ga}$ single crystals," Acta Metallurgica, vol. 21, no. 4, pp. 415-425, 1973.

[22] S. M. Copley, B. H. Kear, and G. M. Rowe, "The temperature and orientation dependence of yielding in Mar-M200 single crystals," Materials Science and Engineering, vol. 10, pp. 87-92, 1972.

[23] D. Hull and D. J. Bacon, Introduction to Dislocations. Elsevier Ltd., 5th ed., 2011.

[24] C. Lall, S. Chin, and D. P. Pope, "The orientation and temperature dependence of the yield stress of $\mathrm{Ni}_{3}(\mathrm{Al}, \mathrm{Nb})$ single crystals," Metallurgical Transactions A, vol. 10, no. 9, pp. 1323-1332, 1979.

[25] M. Feller-Kniepmeier, T. Link, I. Poschmann, G. ScheunemannFrerker, and C. Schulze, "Temperature dependence of deformation mechanisms in a single crystal nickel-base alloy with high volume fraction of $\gamma^{\prime}$ phase," Acta Materialia, vol. 44, no. 6, pp. 2397-2407, 1996.

[26] Q. Qin and J. L. Bassani, "Non-schmid yield behavior in single crystals," Journal of the Mechanics and Physics of Solids, vol. 40, no. 4, pp. 813-833, 1992.

[27] N. Tsuno, S. Shimabayashi, K. Kakehi, C. M. F. Rae, and R. C. Reed, "Tension/compression asymmetry in yield and creep strengths of Nibased superalloys," in Superalloys 2008 (R. C. Reed, K. A. Green, P. Caron, T. P. Gabb, M. G. Fahrman, E. S. Huron, and S. A. Woodard, eds.), pp. 433-442, The Minerals, Metals and Materials Society, 2008.

[28] S. S. Ezz, D. P. Pope, and V. Vitek, "Asymmetry of plastic flow in $\mathrm{Ni}_{3}$ Ga single crystals," Acta Metallurgica, vol. 35, no. 7, pp. 1879-1885, 1987.

[29] S. S. Ezz, D. P. Pope, and V. Paidar, "The tension/compression flow stress asymmetry in $\mathrm{Ni}_{3}(\mathrm{Al}, \mathrm{Nb})$ single crystals," Acta Metallurgica, vol. 30, no. 5, pp. 921-926, 1982.

[30] D. P. Pope and S. S. Ezz, "Mechanical properties of $\mathrm{Ni}_{3} \mathrm{Al}$ and nickelbase alloys with high volume fraction of $\gamma^{\prime}$," International metals reviews, vol. 29, no. 3, pp. 136-167, 1984. 
[31] F. Jiao, D. Bettge, W. Österle, and J. Ziebs, "Tension-compression asymmetry of the (001) single crystal nickel base superalloy SC16 under cyclic loading at elevated temperatures," Acta Materialia, vol. 44, no. 10, pp. 3933-3942, 1996.

[32] M. Yamashita and K. Kakehi, "Tension/compression asymmetry in yield and creep strengths of Ni-based superalloy with a high amount of tantalum," Scripta Materialia, vol. 55, no. 2, pp. 139-142, 2006.

[33] T. Ichitsubo, D. Koumoto, M. Hirao, K. Tanaka, M. Osawa, T. Yokokawa, and H. Harada, "Elastic anisotropy of rafted Ni-base superalloy at high temperatures," Acta Materialia, vol. 51, no. 16, pp. 4863-4869, 2003.

[34] P. Caron, D. Cornu, T. Khan, and J. M. de Monicault, "Development of a hydrogen resistant superalloy for single crystal blade application in rocket engine turbopumps," in Superalloys 1996 (R. D. Kissinger, D. J. Deye, D. L. Anton, A. D. Cetel, M. V. Nathal, T. M. Pollock, and D. A. Woodard, eds.), pp. 53-60, The Minerals, Metals and Materials Society, 1996.

[35] R. V. Miner, R. C. Voigt, J. Gayda, and T. P. Gabb, "Orientation and temperature dependence of some mechanical properties of the singlecrystal nickel-base superalloy René N4: Part I. Tensile behavior," Metallurgical Transactions A, vol. 17A, pp. 491-496, 1986.

[36] T. S. Rong, "Serrated yielding in the B2-ordered Nb-15Al-20V alloy," Intermetallics, vol. 11, pp. 151-155, 2003.

[37] X. Wu, J. H. Zhang, J. L. Liu, T. Jin, Y. B. Xu, and Z. Hu, "Plastic deformation inhomogeneity in a single-crystal nickel-base superalloy," Materials Science and Engineering A, vol. 325, pp. 478-483, 2002.

[38] S. A. Nalawade, M. Sundararaman, R. Kishore, and J. G. Shah, "The influence of aging on the serrated yielding phenomena in a nickel-based superalloy," Scripta Materialia, vol. 59, pp. 991-994, 2008.

[39] T. P. Gabb, J. Gayda, and R. V. Miner, "Orientation and temperature dependence of some mechanical properties of the single-crystal nickel-base superalloy René N4: Part II. Low cycle fatigue behavior," Metallurgical Transactions A, vol. 17A, pp. 497-505, 1986. 
[40] R. V. Miner, T. P. Gabb, J. Gayda, and K. J. Hemker, "Orientation and temperature dependence of some mechanical properties of the singlecrystal nickel-base superalloy René N4: Part III. Tension-compression asymmetry," 1986.

[41] X. H. Li and J. Moverare, "The use of acoustic emission technology in coating ductility testing at variuos temperatures," Proceeding of ASME Turbo Expo, 2004.

[42] E. F. Westbrooke, L. E. Forero, and F. Ebrahimi, "Slip analysis in a Ni-base superalloy," Acta Materialia, vol. 53, no. 7, pp. 2137-2147, 2005.

[43] N. Birks, G. H. Meier, and F. S. Pettit, Introduction to the HighTemperature Oxidation of Metals. Cambridge University Press, 2nd ed., 2006.

[44] S. Draper, D. Hull, and R. Dreshfield, "Observations of directional $\gamma^{\prime}$ coarsening during engine operation," Metallurgical Transactions A, vol. 20, no. 4, pp. 683-688, 1989.

[45] R. C. Reed, D. C. Cox, and C. M. F. Rae, "Kinetics of rafting in a single crystal superalloy: Effects of residual microsegregation," Materials Science and Technology, vol. 23, no. 8, pp. 893-902, 2007.

[46] F. R. N. Nabarro, C. M. Cress, and P. Kotschy, "The thermodynamic driving force for rafting in superalloys," Acta Materialia, vol. 44, pp. 3189-3198, 81996.

[47] T. M. Pollock and A. S. Argon, "Directional coarsening in nickel-base single crystals with high volume fractions of coherent precipitates," Acta Metallurgica et Materialia, vol. 42, pp. 1859-1874, 61994.

[48] M. Doi and T. Miyazaki, " $\gamma^{\prime}$ precipitate morphology formed under the influence of elastic interaction energies in nickel-base alloys," Materials Science and Engineering, vol. 78, no. 1, pp. 87 - 94, 1986.

[49] M. Ignat, J. Y. Buffiere, and J. M. Chaix, "Microstructures induced by a stress gradient in a nickel-based superalloy," Acta Metallurgica et Materialia, vol. 41, no. 3, pp. 855-862, 1993.

[50] J. Buffiere and M. Ignat, "A dislocation based criterion for the raft formation in nickel-based superalloys single crystals," Acta Metallurgica et Materialia, vol. 43, no. 5, pp. 1791 - 1797, 1995. 
[51] R. C. Reed, N. Matan, D. C. Cox, M. A. Rist, and C. M. F. Rae, "Creep of CMSX-4 superalloy single crystals: effects of rafting at high temperature," Acta Materialia, vol. 47, no. 12, pp. 3367-3381, 1999.

[52] L. A. Jacome, P. Nortershauser, J.-K. Heyer, A. Lahni, J. Frenzel, A. Dlouhy, C. Somsen, and G. Eggeler, "High-temperature and lowstress creep anisotropy of single-crystal superalloys," Acta Materialia, vol. 61, pp. 2926-2943, 2013.

[53] J.-B. le Graverend, J. Cormier, M. Jouiad, F. Gallerneau, P. Paulmier, and F. Hamon, "Effect of fine $\gamma^{\prime}$ precipitation on non-isothermal creep and creep-fatigue behaviour of nickel base superalloy MC2," Materials Science and Engineering: A, vol. 527, no. 20, pp. 5295-5302, 2010.

[54] J. Cormier, X. Milhet, and J. Mendez, "Non-isothermal creep at very high temperature of the nickel-based single crystal superalloy MC2," Acta Materialia, vol. 55, no. 18, pp. 6250-6259, 2007.

[55] D. Chatterjee, N. Hazari, N. Das, and R. Mitra, "Microstructure and creep behavior of DMS4-type nickel-based superalloy single crystals with orientations near $\langle 001\rangle$ and $\langle 011\rangle$," Materials Science and Engineering $A$, vol. 528, no. 2, pp. 604-613, 2010.

[56] N. Matan, D. C. Cox, C. M. F. Rae, and R. C. Reed, "On the kinetics of rafting in CMSX-4 superalloy single crystals," Acta Materialia, vol. 47, no. 7, pp. 2031-2045, 1999.

[57] M. Veron, Y. Brechet, and F. Louchet, "Strain induced directional coarsening in Ni based superalloys," Scripta Materialia, vol. 34, no. 12, pp. 1883-1886, 1996.

[58] D. Leidermark, J. J. Moverare, S. Johansson, K. Simonsson, and S. Sjöström, "Tension/compression asymmetry of a single-crystal superalloy in virgin and degraded condition," Acta Materialia, vol. 58, no. 15 , pp. 4986-4997, 2010.

[59] A. Fredholm and J. L. Strudel, "On the creep resistance of some nickel base single crystals," in Superalloys 1984 (R. H. Bricknell, W. B. Kent, M. Gell, C. S. Kortovich, and J. F. Radavich, eds.), pp. 211-220, Metallurgical Society of AIME, 1984.

[60] M. Ott and H. Mughrabi, "Dependence of the high-temperature lowcycle fatigue behaviour of the monocrystalline nickel-base superalloys 
CMSX-4 and CMSX-6 on the $\gamma / \gamma^{\prime}$-morphology," Materials Science and Engineering: A, vol. 272, no. 1, pp. 24-30, 1999.

[61] H. Mughrabi and U. Tetzlaff, "Microstructure and high-temperature strength of monocrystalline nickel-base superalloys," Advanced Engineering Materials, vol. 2, no. 6, pp. 319-326, 2000.

[62] M. Ott and H. Mughrabi, "Dependence of the isothermal fatigue behaviour of a monocrystalline nickel-base superalloy on the $\gamma / \gamma^{\prime}$ morphology," Proceedings, FATIGUE, vol. 2, pp. 789-794, 1996.

[63] P. Li, Q. Q. Li, T. Jin, Y. Z. Zhou, J. G. Li, X. F. Sun, and Z. F. Zhang, "Effect of Re on low-cycle fatigue behaviors of Ni-based singlecrystal superalloys at $900{ }^{\circ} \mathrm{C}, "$ Materials Science and Engineering: A, vol. 603, pp. 84-92, 2014.

[64] P. Li, Q. Li, T. Jin, Y. Zhou, J. Li, X. Sun, and Z. Zhang, "Comparison of low-cycle fatigue behaviors between two nickel-based single-crystal superalloys," International Journal of Fatigue, vol. 63, no. 0, pp. 137 $144,2014$.

[65] F. C. Neuner, U. Tetzlaff, and H. Mughrabi, "Enhancement of thermomechanical fatigue resistance of a monocrystalline nickel-base superalloy by pre-rafting," in Thermomechanical fatigue of Materials, ASTM STP 1428, pp. 112-126, 2003.

[66] U. Tetzlaff and H. Mughrabi, "Enhancement of the high-temperature tensile creep strength of monocrystalline nickel-base superalloys by prerafting in compression," in Superalloys 2000 (T. M. Pollock, R. D. Kissinger, R. R. Bowman, K. A. Green, M. McLean, S. Olson, and J. J. Schirra, eds.), pp. 273-282, The Minerals, Metals and Materials Society, 2000.

[67] R. P. Dalal, C. R. Thomas, and L. E. Dardi, "The effect of crystallographic orientation on the physical and mechanical properties of an investment cast single-crystal nickel-base superalloy," in Superalloys 1984 (R. H. Bricknell, W. B. Kent, M. Gell, C. S. Kortovich, and J. F. Radavich, eds.), pp. 185-197, Metallurgical Society of AIME, 1984.

[68] D. Shi, J. Huang, X. Yang, and H. Yu, "Effects of crystallographic orientations and dwell types on low cycle fatigue and life modeling of a SC superalloy," International Journal of Fatigue, vol. 49, no. 0, pp. 31-39, 2013. 
[69] B. Wang, D. Liu, Z. Wen, and Z. Yue, "Tension/compression asymmetry of [001] single-crystal nickel-based superalloy \{DD6 $\}$ during low cycle fatigue," Materials Science and Engineering: A, vol. 593, no. 0, pp. $31-37,2014$.

[70] T. P. Gabb and G. Welsch, "The high temperature deformation in cyclic loading of a single crystal nickel-base superalloy," Acta Metallurgica, vol. 37, no. 9, pp. 2507-2516, 1989.

[71] T. P. Gabb, G. Welsch, R. V. Miner, and J. Gayda, "The low cycle fatigue deformation response of a single-crystal superalloy at $650{ }^{\circ} \mathrm{C}$," Materials Science and Engineering A, vol. 108, pp. 189-202, 1989.

[72] H. Zhou, Y. Ro, H. Harada, Y. Aoki, and M. Arai, "Deformation microstructures after low-cycle fatigue in a fourth-generation Ni-base SC superalloy TMS-138," Materials Science and Engineering: A, vol. 381, no. 1-2, pp. $20-27,2004$.

[73] A. Pineau and S. D. Antolovich, "High temperature fatigue of nickelbase superalloys - a review with special emphasis on deformation modes and oxidation," Engineering Failure Analysis, vol. 16, pp. 2668-2697, 122009.

[74] H. Hong, B. Choi, I. Kim, Y. Yoo, and C. Jo, "Characterization of deformation mechanisms during low cycle fatigue of a singlecrystal nickel-based superalloy," Journal of Materials Science, vol. 46, pp. 5245-5251, 2011.

[75] J. Yu, X. Sun, T. Jin, N. Zhao, H. Guan, and Z. Hu, "High temperature creep and low cycle fatigue of a nickel-base superalloy," Materials Science and Engineering: A, vol. 527, no. 9, pp. 2379-2389, 2010.

[76] P. Caron, T. Khan, and Y. G. Nakagawa, "Effect of orientation on the intermediate temperature creep behaviour of Ni-base single crystal superalloys," Scripta Metallurgica, vol. 20, no. 4, pp. 499-502, 1986.

[77] P. Lukas, J. Cadek, V. Sustek, and L. Kunz, "Creep of CMSX-4 singlecrystals of different crystal orientations in tension and compression," Materials Science and Engineering A, vol. 208, pp. 149-157, 1996.

[78] K. Kakehi, "Tension/compression asymmetry in creep behavior of a Ni-based superalloy," Scripta Materialia, vol. 41, pp. 461-465, 1999. 
[79] K. Kakehi, "Effect of primary and secondary precipitates on creep strength of Ni-base superalloy single-crystals," Materials Science and Engineering A, vol. 278, pp. 135-141, 2000.

[80] J. Courbon, M. Ignat, and F. Louchet, "Compression creep of $\langle 110\rangle$ oriented single crystals of nickel-base superalloy CMSX-2," Acta Metallurgica et Materialia, vol. 38, pp. 663-670, 41990.

[81] D. L. Anton and F. D. Lemkey, "Quinary alloy modification of the eutectic superalloy $\gamma / \gamma^{\prime}+\mathrm{Cr}_{3} \mathrm{C}_{2}$," in Superalloys 1984 (R. H. Bricknell, W. B. Kent, M. Gell, C. S. Kortovich, and J. F. Radavich, eds.), pp. 601-610, Metallurgical Society of AIME, 1984.

[82] A. F. Giamei and D. L. Anton, "Rhenium additions to a Ni-base superalloy: Effects on the microstructure," Metallurgical Transactions A, vol. 16A, pp. 1997-2005, 1985.

[83] S. Tian, J. Wu, D. Shu, Y. Su, H. Yu, and B. Qian, "Influence of element re on deformation mechanism within $\gamma^{\prime}$-phase of single crystal nickel-based superalloys during creep at elevated temperatures," $M a$ terials Science and Engineering: A, vol. 616, pp. 260-267, 2014.

[84] D. Blavette, P. Caron, and T. Khan, "An atom probe investigation of the role of rhenium additions in improving creep resistance of Ni-base superalloys," Scripta Metallurgica, vol. 20, pp. 1395-1400, 1986.

[85] A. Mottura, M. W. Finnis, and R. C. Reed, "On the possibility of rhenium clustering in nickel-based superalloys," Acta Materialia, vol. 60, pp. 2866-2872, 2012.

[86] A. Mottura, R. Wu, M. Finnis, and R. Reed, "A critique of rhenium clustering in ni-re alloys using extended x-ray absorption spectroscopy," Acta Materialia, vol. 56, no. 11, pp. 2669 - 2675, 2008.

[87] A. Mottura, N. Warnken, M. Miller, M. Finnis, and R. Reed, "Atom probe tomography analysis of the distribution of rhenium in nickel alloys," Acta Materialia, vol. 58, no. 3, pp. 931 - 942, 2010.

[88] S. Steuer, Z. Hervier, S. Thabart, C. Castaing, T. Pollock, and J. Cormier, "Creep behavior under isothermal and non-isothermal conditions of AM3 single crystal superalloy for different solutioning cooling rates," Materials Science and Engineering: A, vol. 601, pp. 145-152, 2014. 
[89] J.-B. le Graverend, J. Cormier, S. Kruch, F. Gallerneau, and J. Mendez, "Microstructural parameters controlling high-temperature creep life of the nickel-base single-crystal superalloy MC2," Metallurgical and Materials Transactions A, vol. 43A, pp. 3988-3997, 2012.

[90] G. M. Han, J. J. Yu, X. F. Sun, and Z. Q. Hu, "Thermo-mechanical fatigue behavior of a single-crystal nickel-based superalloy," Materials Science and Engineering A, vol. 528, pp. 6217-6224, 2011.

[91] J. X. Zhang, H. Harada, Y. Ro, Y. Koizumi, and T. Kobayashi, "Thermomechanical fatigue mechanism in a modern single crystal nickel base superalloy TMS-82," Acta Materialia, vol. 56, no. 13, pp. 2975-2987, 2008.

[92] J. X. Zhang, H. Harada, Y. Koizumi, and T. Kobayashi, "Crack appearance of single-crystal nickel-base superalloys after thermomechanical fatigue failure," Scripta Materialia, vol. 61, no. 12, pp. 1105-1108, 2009.

[93] ASTM, ASTM E2368 - 10, Standard practice for strain controlled thermomechanical fatigue testing.

[94] ISO, ISO 12111:2011(E), Metallic materials - Fatigue testing - Straincontrolled thermomechanical fatigue testing method.

[95] P. Hähner, E. Affeldt, T. Beck, H. Klingelhöffer, M. Loveday, and C. Rinaldi, Validated Code-of-Practice for Strain-Controlled ThermoMechanical Fatigue testing. European Commission, Joint Research Centre, 2006.

[96] F. Liu, Z. G. Wang, S. H. Ai, Y. C. Wang, X. F. Sun, T. Jin, and H. R. Guan, "Thermo-mechanical fatigue of single crystal nickel-based superalloy DD8," Scripta Materialia, vol. 48, pp. 1265-1270, 52003.

[97] J. Yu, G. Han, Z. Chu, X. Sun, T. Jin, and Z. Hu, "High temperature thermo-mechanical and low cycle fatigue behaviors of DD single crystal superalloy," Materials Science and Engineering: A, vol. 592, pp. 164$172,2014$.

[98] M. R. Hirsch, R. L. Amaro, S. D. Antolovich, and R. W. Neu, "Coupled thermomechanical high cycle fatigue in a single crystal Ni-base superalloy," International Journal of Fatigue, vol. 62, pp. 53-61, 52014. 
[99] F. Sun, J. Zhang, and H. Harada, "Deformation twinning and twinningrelated fracture in nickel-base single-crystal superalloys during thermomechanical fatigue cycling," Acta Materialia, vol. 67, pp. 45 - 57, 2014.

[100] A. Sato, J. J. Moverare, M. Hasselqvist, and R. C. Reed, "On the mechanical behavior of a new single-crystal superalloy for industrial gas turbine applications," Metallurgical and Materials Transactions A, vol. 43A, pp. 2302-2315, 2012.

[101] X. Z. Lv, J. X. Zhang, and H. Harada, "Twinning behaviors during thermomechanical fatigue cycling of a nickel-base single-crystal TMS82 superalloy," Journal of Materials Engineering and Performance, vol. 23, no. 3, pp. 766-771, 2014.

[102] J. J. Moverare, M. Segersäll, A. Sato, S. Johansson, and R. C. Reed, "Thermomechanical fatigue of single-crystal superalloys: Influence of compositions and microstructure," in Superalloys 2012 (E. S. Huron, R. C. Reed, M. Hardy, M. J. Mills, R. E. Montero, P. D. Portella, and J. Talesman, eds.), pp. 369-377, The Minerals, Metals and Materials Society, 2012.

[103] L. Kovarik, R. Unocic, J. Li, P. Sarosi, C. Shen, Y. Wang, and M. Mills, "Microtwinning and other shearing mechanisms at intermediate temperatures in Ni-based superalloys," Progress in Materials Science, vol. 54, no. 6, pp. 839-873, 2009.

[104] L. Kovarik, R. R. Unocic, J. Li, and M. J. Mills, "The intermediate temperature deformation of Ni-based superalloys: Importance of reordering," JOM, vol. 61, no. 2, pp. 42-48, 2009.

[105] Y. Xu, K. Du, C. Cui, and H. Ye, "Deformation twinning with zero macroscopic strain in a coarse-grained Ni-Co-based superalloy," Scripta Materialia, vol. 77, pp. 71-74, 2014.

[106] J. X. Zhang, H. Harada, Y. Ro, and Y. Koizumi, "Superior thermomechanical fatigue property of a superalloy due to its heterogeneous microstructure," Scripta Materialia, vol. 55, no. 8, pp. 731-734, 2006.

[107] J. X. Zhang, Y. Ro, H. Zhou, and H. Harada, "Deformation twins and failure due to thermo-mechanical cycling in TMS-75 superalloy," Scripta Materialia, vol. 54, pp. 655-660, 2006. 
[108] A. Yeh and S. Tin, "Effects of Ru and Re additions on the high temperature flow stresses of Ni-base single crystal superalloys," Scripta Materialia, vol. 52, no. 6, pp. 519-524, 2005.

[109] T. Yokokawa, M. Osawa, K. Nishida, T. Kobayashi, Y. Koizumi, and H. Harada, "Partitioning behavior of platinum group metals on the $\gamma$ and $\gamma^{\prime}$ phases of Ni-base superalloys at high temperatures," Scripta Materialia, vol. 49, no. 10, pp. 1041-1046, 2003.

[110] H. Hong, J. Yoon, B. Choi, I. Kim, Y. Yoo, and C. Jo, "Localized microtwin formation and failure during out-of-phase thermomechanical fatigue of a single crystal nickel-based superalloy," International Journal of Fatigue, vol. 69, pp. 22-27, 2013.

[111] B. Fu, J. Zhang, and H. Harada, "Interaction between crack and twins in TMS-82 superalloy during thermomechanical fatigue process," Progress in Natural Science: Materials International, vol. 23, no. 5, pp. 508-513, 2013.

[112] B. Fu, J. Zhang, and H. Harada, "Significant thinning of deformation twins and its effect on thermomechanical fatigue fracture in nickel base single crystal superalloys," Materials Science and Engineering: A, vol. 605, pp. 253-259, 2014.

[113] J. J. Moverare, S. Johansson, and R. C. Reed, "Deformation and damage mechanisms during thermal-mechanical fatigue of a single-crystal superalloy," Acta Materialia, vol. 57, no. 7, pp. 2266-2276, 2009.

[114] J. J. Moverare and S. Johansson, "Damage mechanisms of a high-Cr single crystal superalloy during thermomechanical fatigue," Materials Science and Engineering: A, vol. 527, no. 3, pp. 553-558, 2010.

[115] H. U. Hong, J. G. Kang, B. G. Choi, I. S. Kim, Y. S. Yoo, and C. Y. Jo, "A comparative study on thermomechanical and low cycle fatigue failures of a single crystal nickel-based superalloy," International Journal of Fatigue, vol. 33, pp. 1592-1599, 122011.

[116] "Patent wo2008046708a1, Nickel-Base Superalloys."

[117] R. C. Reed, J. J. Moverare, A. Sato, F. Karlsson, and M. Hasselqvist, "A new single-crystal superalloy for power generation applications," in Superalloys 2012 (E. S. Huron, R. C. Reed, M. Hardy, M. J. Mills, R. E. Montero, P. D. Portella, and J. Talesman, eds.), pp. 197-204, The Minerals, Metals and Materials Society, 2012. 
[118] A. Sato, Y.-L. Chiu, and R. Reed, "Oxidation of nickel-based singlecrystal superalloys for industrial gas turbine applications," Acta Materialia, vol. 59, no. 1, pp. 225 - 240, 2011.

[119] P. Kontis, H. A. M. Yusof, K. Moore, and C. R. M., "On the effect of boron on the mechanical properties of a new polycrystalline superalloy," in EUROSUPERALLOYS 2014 - 2nd European Symposium on Superalloys and their Applications, vol. 14, pp. 17003.1-17003.6, 2014. 

Part II

Papers Included 


\section{Papers}

The articles associated with this thesis have been removed for copyright reasons. For more details about these see:

http://urn.kb.se/resolve?urn=urn:nbn:se:liu:diva-111643 